\title{
Multiple molecular mechanisms form a positive feedback loop driving amyloid $\beta 42$ peptide-induced neurotoxicity via activation of the TRPM2 channel in hippocampal neurons
}

\author{
Xin Li ${ }^{1}$ and Lin-Hua Jiang $\mathbb{1}^{1,2}$
}

\begin{abstract}
Emerging evidence supports an important role for the ROS-sensitive TRPM2 channel in mediating age-related cognitive impairment in Alzheimer's disease (AD), particularly neurotoxicity resulting from generation of excessive neurotoxic $A \beta$ peptides. Here we examined the elusive mechanisms by which $A \beta_{42}$ activates the TRPM2 channel to induce neurotoxicity in mouse hippocampal neurons. $A \beta_{42}$-induced neurotoxicity was ablated by genetic knockout (TRPM2-KO) and attenuated by inhibition of the TRPM2 channel activity or activation through PARP-1. A $\beta_{42}$-induced neurotoxicity was also inhibited by treatment with TPEN used as a $\mathrm{Zn}^{2+}$-specific chelator. Cell imaging revealed that $\mathrm{A} \beta_{42}$-induced lysosomal dysfunction, cytosolic $\mathrm{Zn}^{2+}$ increase, mitochondrial $\mathrm{Zn}^{2+}$ accumulation, loss of mitochondrial function, and mitochondrial generation of ROS. These effects were suppressed by TRPM2-KO, inhibition of TRPM2 or PARP-1, or treatment with TPEN. Bafilomycin-induced lysosomal dysfunction also resulted in TRPM2-dependent cytosolic $\mathrm{Zn}^{2+}$ increase, mitochondrial $\mathrm{Zn}^{2+}$ accumulation, and mitochondrial generation of ROS, supporting that lysosomal dysfunction and accompanying $\mathrm{Zn}^{2+}$ release trigger mitochondrial $\mathrm{Zn}^{2+}$ accumulation and generation of ROS. $A \beta_{42}$-induced effects on lysosomal and mitochondrial functions besides neurotoxicity were also suppressed by inhibition of PKC and NOX. Furthermore, $A \beta_{42}$-induced neurotoxicity was prevented by inhibition of MEK/ERK. Therefore, our study reveals multiple molecular mechanisms, including PKC/NOX-mediated generation of ROS, activation of MEK/ERK and PARP-1, lysosomal dysfunction and $\mathrm{Zn}^{2+}$ release, mitochondrial $\mathrm{Zn}^{2+}$ accumulation, loss of mitochondrial function, and mitochondrial generation of ROS, are critically engaged in forming a positive feedback loop that drives $A \beta_{42}$-induced activation of the TRPM2 channel and neurotoxicity in hippocampal neurons. These findings shed novel and mechanistic insights into AD pathogenesis.
\end{abstract}

Correspondence: L-H. Jiang (I.h.jiang@leeds.ac.uk)

${ }^{1}$ School of Biomedical Sciences, Faculty of Biological Sciences, University of Leeds, Leeds, UK

${ }^{2}$ Sino-UK Joint Laboratory of Brain Function and Injury of Henan Province and Department of Physiology and Neurobiology, Xinxiang Medical University, Xinxiang, China

Edited by A. Verkhratsky

\section{Introduction}

Alzheimer's disease (AD) is an age-related neurodegenerative disorder characterized by progressive cognitive impairments and representing the most prevalent cause of dementia among the elder people. One histopathological hallmark of $\mathrm{AD}$ is the formation of senile amyloid plaque with deposits of amyloid $\beta$ (A $\beta$ ) peptides resulting from proteolytic cleavage of amyloid precursor protein (APP) 
by presenilin-1 (PS-1) containing $\gamma$-secretase ${ }^{1}$. It is known that $A \beta$ induce neurotoxicity via multiple but yet not fully understood mechanisms, leading to synaptic loss and network dysfunction in hippocampus and other brain regions $^{2}$. For example, $A \beta$ can stimulate generation of reactive oxygen species (ROS) in hippocampal neurons ${ }^{3}$. In addition, lipid peroxides and oxidative modifications of proteins and lipids are widely observed in cells exposed to $\mathrm{A} \beta$ and in the brain of transgenic APP/PS-1 AD mice, consistent with a role for oxidative stress in $A \beta$-induced neurotoxicity ${ }^{4,5} \cdot \mathrm{Zn}^{2+}$, as one of the most common trace elements in human body, has numerous structural and regulatory functions, but it is highly neurotoxic ${ }^{6,7} \cdot \mathrm{Zn}^{2+}$ can enhance oxidative stress via impairing mitochondrial function and inducing mitochondrial generation of ROS or activating other ROS-generating mechanisms such as NADPH-dependent oxidases (NOX) ${ }^{8,9}$. In fact, NOX are an important source of ROS that induce neuronal death implicated in ischemic stroke and $\mathrm{AD}^{10,11}$. Conversely, oxidative stress can elevate the cytosolic $\mathrm{Zn}^{2+}$ concentration $\left(\left[\mathrm{Zn}^{2+}\right]_{\mathrm{c}}\right)$ by activating diverse $\mathrm{Ca}^{2+} / \mathrm{Zn}^{2}$ ${ }^{+}$-transporting mechanisms that mediate extracellular $\mathrm{Zn}^{2+}$ influx and/or $\mathrm{Zn}^{2+}$ release from intracellular organelles such as lysosome, or inducing $\mathrm{Zn}^{2+}$ release from cytosolic $\mathrm{Zn}^{2+}$-binding metallothioneins ${ }^{6,7,12-15}$. Such intimate relationships of ROS and $\mathrm{Zn}^{2+}$ in neurotoxicity are well-documented under ischemic stroke but less understood in $\mathrm{AD}$, particularly $\mathrm{A} \beta$-induced neurotoxicity.

Transient receptor potential melastatin-related 2 (TRPM2) is a $\mathrm{Ca}^{2+}$-permeable channel primarily located on cell surface ${ }^{16,17}$ and also function as a lysosomal $\mathrm{Ca}^{2}$ ${ }^{+}$-release channel in pancreatic $\beta$-cells and dendritic cells $^{18,19}$. TRPM2 channel is gated by intracellular ADPribose (ADPR), and potently activated by ROS, mainly via stimulating ADPR-generating mechanisms ${ }^{20,21}$, and confers susceptibility to ROS-induced cell death ${ }^{22}$ in numerous cell types ${ }^{20,23}$. For example, TRPM2 channel mediates neuronal death in vitro induced by $\mathrm{H}_{2} \mathrm{O}_{2}$ and ROS-inducing stimuli including $A \beta_{42}$, or under in vivo conditions known to promote generation of ROS such as ischemic stroke ${ }^{24-31}$. Consistently with an early in vitro study suggesting a role for the TRPM2 channel in $A \beta_{42^{-}}$ induced neurotoxicity ${ }^{24}$, a recent study shows that genetic ablation of TRPM2 in the APP/PS-1 mice prevented neurotoxicity and age-related memory impairment ${ }^{32}$, supporting a causative relationship of the TRPM2 channel with $A D$, particularly $A \beta$-induced neurotoxicity and cognitive dysfunction. However, it remained elusive how $A \beta$ activate the TRPM2 channel to induce neurotoxicity. Our recent study shows an exclusive role for the TRPM2 channel in elevating the $\left[\mathrm{Zn}^{2+}\right]_{\mathrm{c}}$ that is critical in postischemia hippocampal neuronal death and impaired learning and memory ${ }^{30}$. In this study, we aimed to elucidate the mechanisms for $A \beta_{42}$-induced TRPM2 channel activation, alteration in intracellular $\mathrm{Zn}^{2+}$ homeostasis and neurotoxicity in hippocampal neurons.

\section{Results \\ TRPM2 in $A \boldsymbol{\beta}_{\mathbf{4 2}}$-induced hippocampal neurotoxicity}

To investigate TRPM2 in mediating $A \beta$-induced neurotoxicity, we started with PI-staining assay to determine hippocampal neuronal death induced by $\mathrm{A} \beta_{42}$, the major neurotoxic $A \beta^{33}$. Exposure to $A \beta_{42}$ at 100 and $300 \mathrm{ng} / \mathrm{ml}$ ( 22 and $66 \mathrm{nM})$ for $24-96 \mathrm{~h}$ led to significant neuronal death in wild-type (WT) neurons (supplementary Fig.1). Exposure to $1 \mu \mathrm{M} \mathrm{A} \beta_{42}$ resulted in greater neuronal death (Fig. 1a,b) and, by contrast, exposure to $1 \mu \mathrm{M} \mathrm{A} \beta_{42-1}$, the peptide with a reversal sequence, caused minimal neuronal death (Fig. 1c; supplementary Fig.2). A $\beta_{42}$-induced neurotoxicity was not observed in TRPM2-knockout (TRPM2-KO) neurons (Fig. 1a,b; supplementary Fig.1). Treatment of WT neurons with $10 \mu \mathrm{M} 2$-APB or $1 \mu \mathrm{M}$ ACA, two TRPM2 channel inhibitors ${ }^{20}$, strongly suppressed $A \beta_{42}$-induced neurotoxicity (Fig. 1d). These results provide genetic and pharmacological evidence to demonstrate a critical role for the TRPM2 channel in neurotoxicity induced by $A \beta_{42}$ at biologically relevant concentrations, in agreement with a recent study showing prevention by TRPM2-KO of hippocampal neurotoxicity due to excessive A $\beta$ generation in the APP/PS- 1 mice ${ }^{32}$. Treatment with $1 \mu \mathrm{M}$ PJ34 or $30 \mu \mathrm{M} \mathrm{DPQ}$, two poly (ADPR) polymerase-1 (PARP-1) inhibitors, also significantly attenuated $A \beta_{42}$-induced neurotoxicity (supplementary Fig.3), consistent with engagement of PARP-1 in $A \beta_{42}$-induced TRPM2 channel activation and neurotoxicity, as previously suggested ${ }^{24}$.

\section{TRPM2 in $\mathrm{A}_{42}$-induced increase in the $\left[\mathrm{Zn}^{2+}\right]_{\mathrm{C}}$ and lysosome dysfunction}

We recently show a critical role of TRPM2-dependent increase in the $\left[\mathrm{Zn}^{2+}\right]_{\mathrm{c}}$ in post-ischemia hippocampal neuronal death ${ }^{30}$. Therefore, we examined whether TRPM2-dependent alteration in intracellular $\mathrm{Zn}^{2+}$ homeostasis is important in $A \beta_{42}$-induced neurotoxicity. Treatment with $100 \mathrm{nM}$ TPEN, as a selective $\mathrm{Zn}^{2+}$ chelator ${ }^{34}$, almost completely prevented $\mathrm{A} \beta_{42}$-induced neurotoxicity (Fig. 1d), indicating a vital role of a rising $\left[\mathrm{Zn}^{2}\right.$ $\left.{ }^{+}\right]_{\mathrm{c}}$ in $\mathrm{A} \beta_{42}$-induced neurotoxicity. We used single-cell imaging and Fluozin3, an indicator for labile $\mathrm{Zn}^{2+}$, to examine the $\left[\mathrm{Zn}^{2+}\right]_{\mathrm{c}}$ in individual hippocampal neurons. As reported previously ${ }^{30}$, the $\left[\mathrm{Zn}^{2+}\right]_{\mathrm{c}}$ in untreated neurons was low and $\mathrm{Zn}^{2+}$ was mainly concentrated in discrete puncta. Here, we further showed that such $\mathrm{Zn}^{2+}$ puncta exhibited strong co-localization with LysoTracker, but not with MitoTracker (supplementary Fig.4), indicating that $\mathrm{Zn}^{2+}$ is predominantly of lysosomal origin, as recently reported in pancreatic $\beta$-cells and endothelial cells ${ }^{35,36}$. Exposure of WT neurons to $A \beta_{42}$ for $24-48 \mathrm{~h}$ 


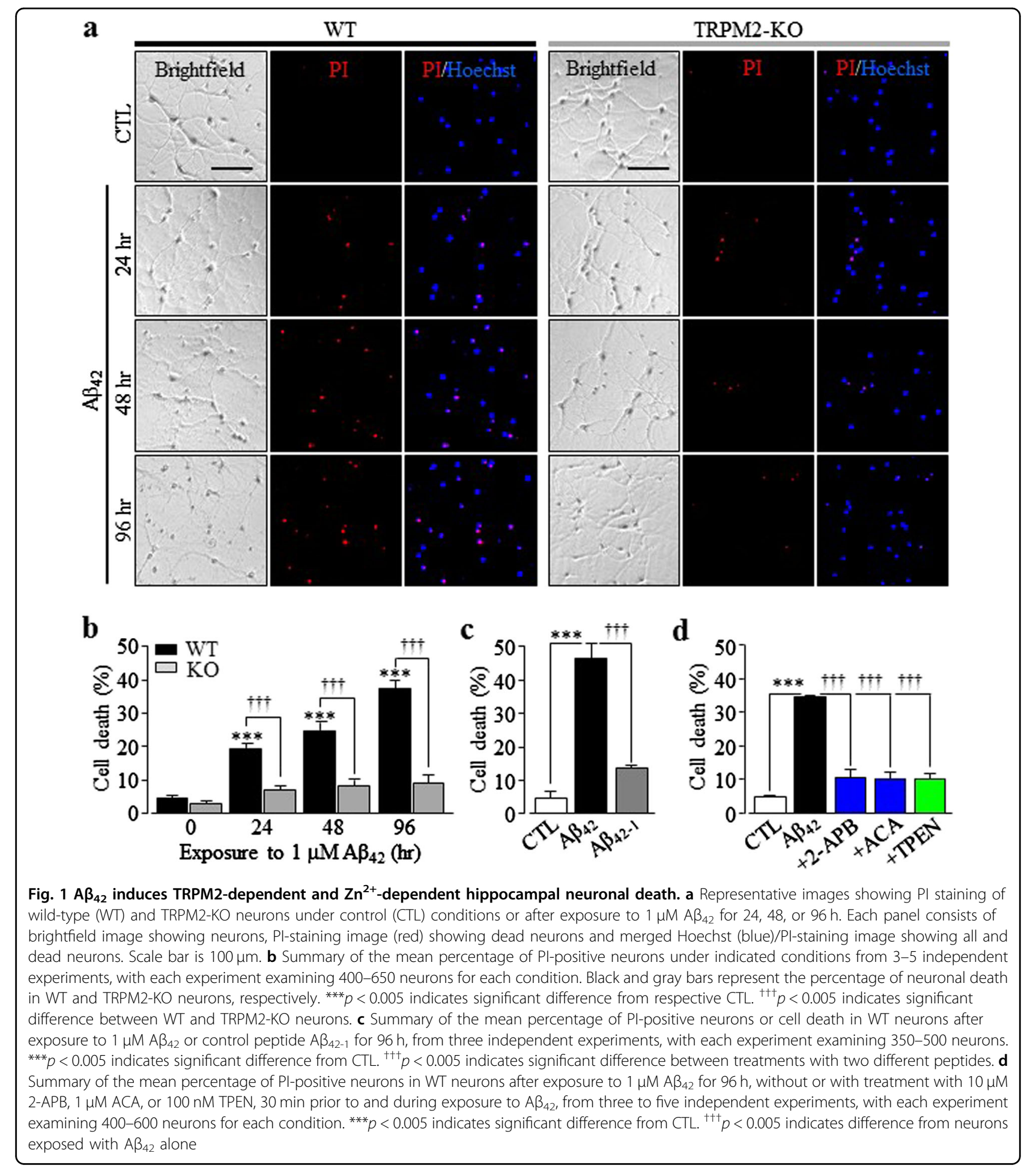

induced a salient increase in the $\left[\mathrm{Zn}^{2+}\right]_{\mathrm{c}}$, and noticeable decline in LysoTracker intensity that suggests lysosomal dysfunction (Fig. 2a,b). However, $\mathrm{A} \beta_{42}$ induced no discernible change in the $\left[\mathrm{Zn}^{2+}\right]_{\mathrm{c}}$ or LysoTracker intensity in TRPM2-KO neurons (Fig. 2a,b). A $\beta_{42}$-induced increase in the $\left[\mathrm{Zn}^{2+}\right]_{\mathrm{c}}$ and reduction in LysoTracker intensity were strongly suppressed by treatment with $1 \mu \mathrm{M}$ PJ34 and 10 $\mu \mathrm{M}$ 2-APB (Fig. 2c,d) or $100 \mathrm{nM}$ TPEN (Fig. 2e,f). Collectively, these results show that the TRPM2 channel is crucial for $\mathrm{A} \beta_{42}$-induced increase in the $\left[\mathrm{Zn}^{2+}\right]_{\mathrm{c}}$ and 

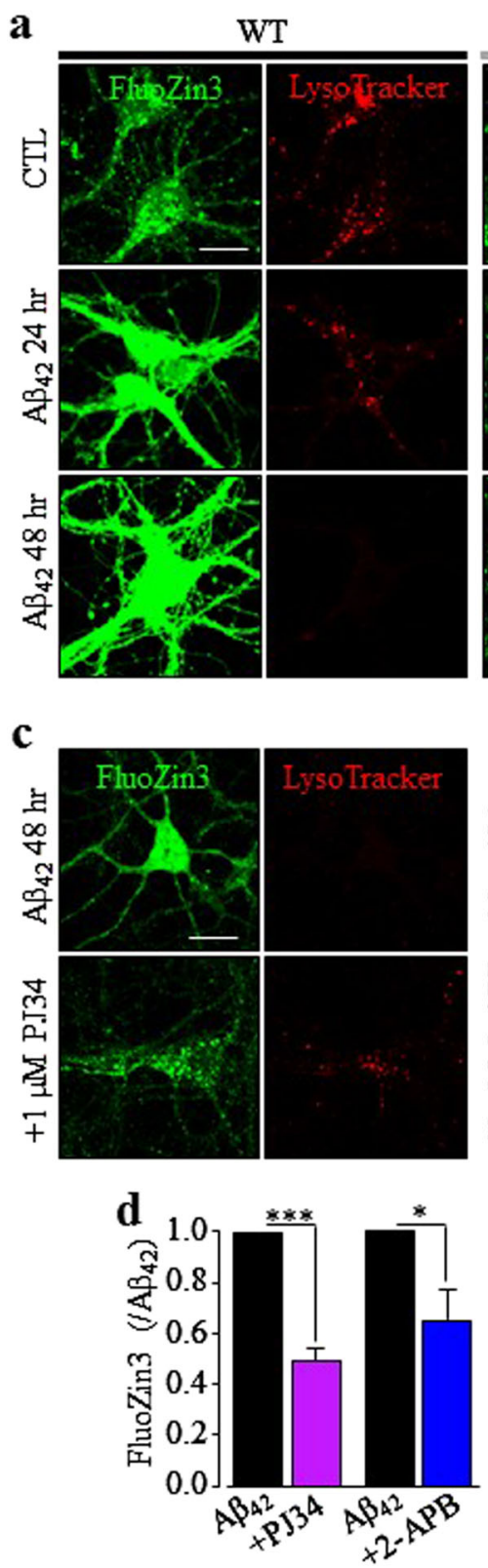
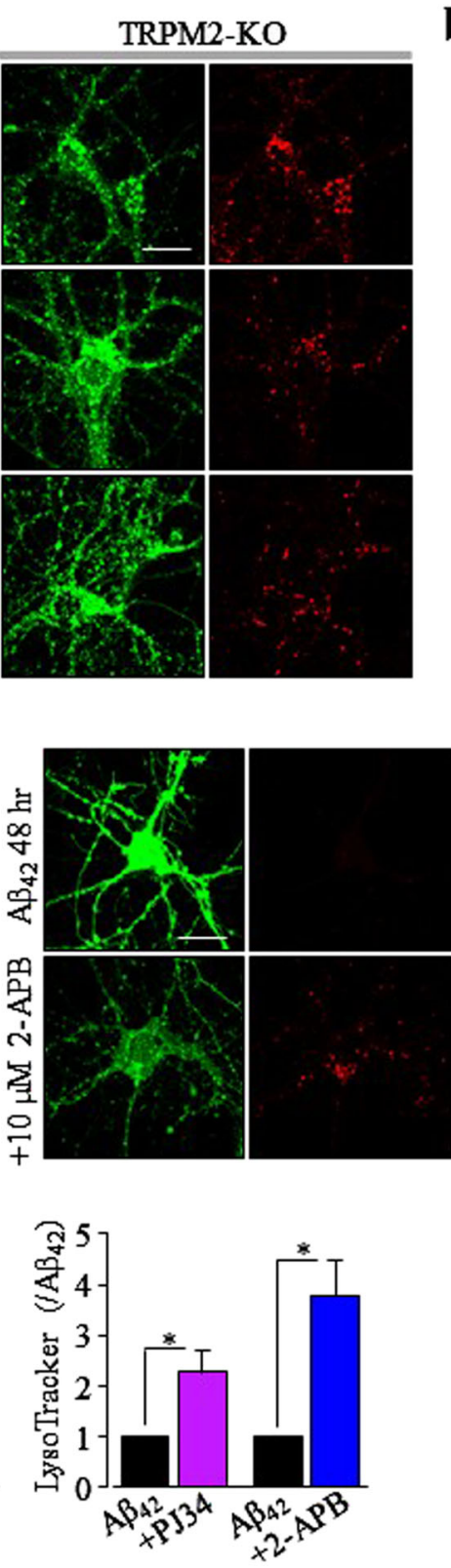

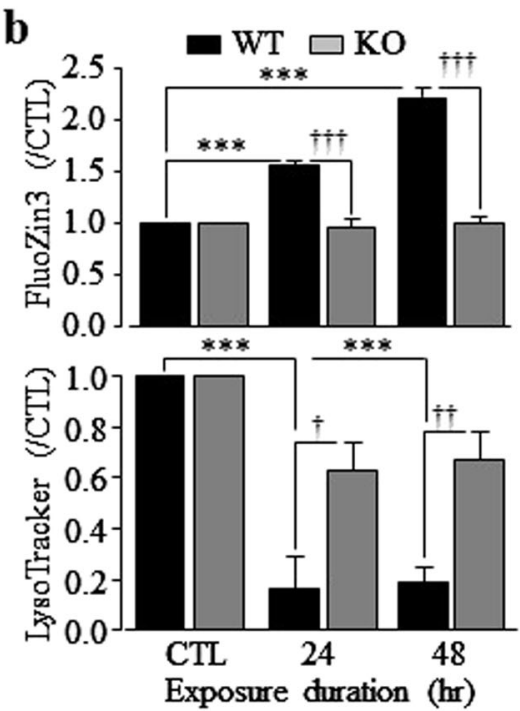

e
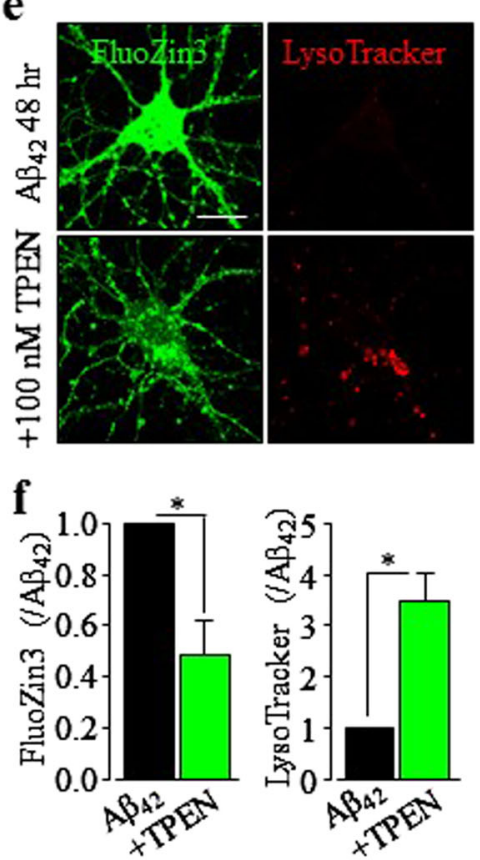

Fig. $2 \mathrm{~A} \beta_{42}$ induces TRPM2-dependent increase in the $\left[\mathrm{Zn}^{2+}\right]_{c}$ and lysosomal dysfunction in hippocampal neurons. a, $c$, e Representative confocal images showing FluoZin3 (green) and LysoTracker (red) staining of wild-type (WT) and TRPM2-KO neurons under control (CTL) conditions or

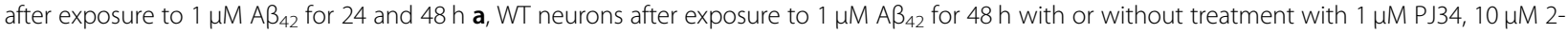
APB c, or $100 \mathrm{nM}$ TPEN e, 30 min prior to and during exposure to $A \beta_{42}$. Scale bar is $10 \mu \mathrm{m}$. $\mathbf{b}$, $\mathbf{d}$, f Summary of the mean fluorescence intensity of FluoZin3 (top panel in $\mathbf{b}$, and left panel in $\mathbf{d}$ and $\mathbf{f}$ ) or LysoTracker (bottom panel in $\mathbf{b}$, and right panel in $\mathbf{d}$ and $\mathbf{f}$ ) under indicated conditions, from three to four independent experiments, with each experiment examining 10-15 neurons for each condition. ${ }^{*} p<0.05$; and ${ }^{* * *} p<0.005$ indicate significant difference from CTL $\mathbf{b}$ or neurons treated with $A \beta_{42}$ alone $(\mathbf{d}, \mathbf{f}) .{ }^{\dagger} p<0.05 ;{ }^{\dagger+} p<0.01$; and ${ }^{++\dagger} p<0.005$ indicate significant difference between WT and TRPM2-KO neurons $\mathbf{b}$

lysosomal dysfunction. To provide further evidence to demonstrate $\mathrm{A} \beta_{42}$-induced lysosomal dysfunction, we performed single-cell imaging using acridine orange (AO), a fluorescence indicator that emits red fluorescence when it is entrapped in lysosome. As a positive control, bafilomycin caused complete loss of AO fluorescence (supplementary Fig.5a). Exposure to $A \beta_{42}$ for $96 \mathrm{~h}$ significantly reduced the AO intensity in WT but not TRPM2-KO neurons (supplementary Fig. $5 \mathrm{a}-\mathrm{c}$ ), supporting $\mathrm{A} \beta_{42}$-induced TRPM2dependent lysosomal dysfunction. 


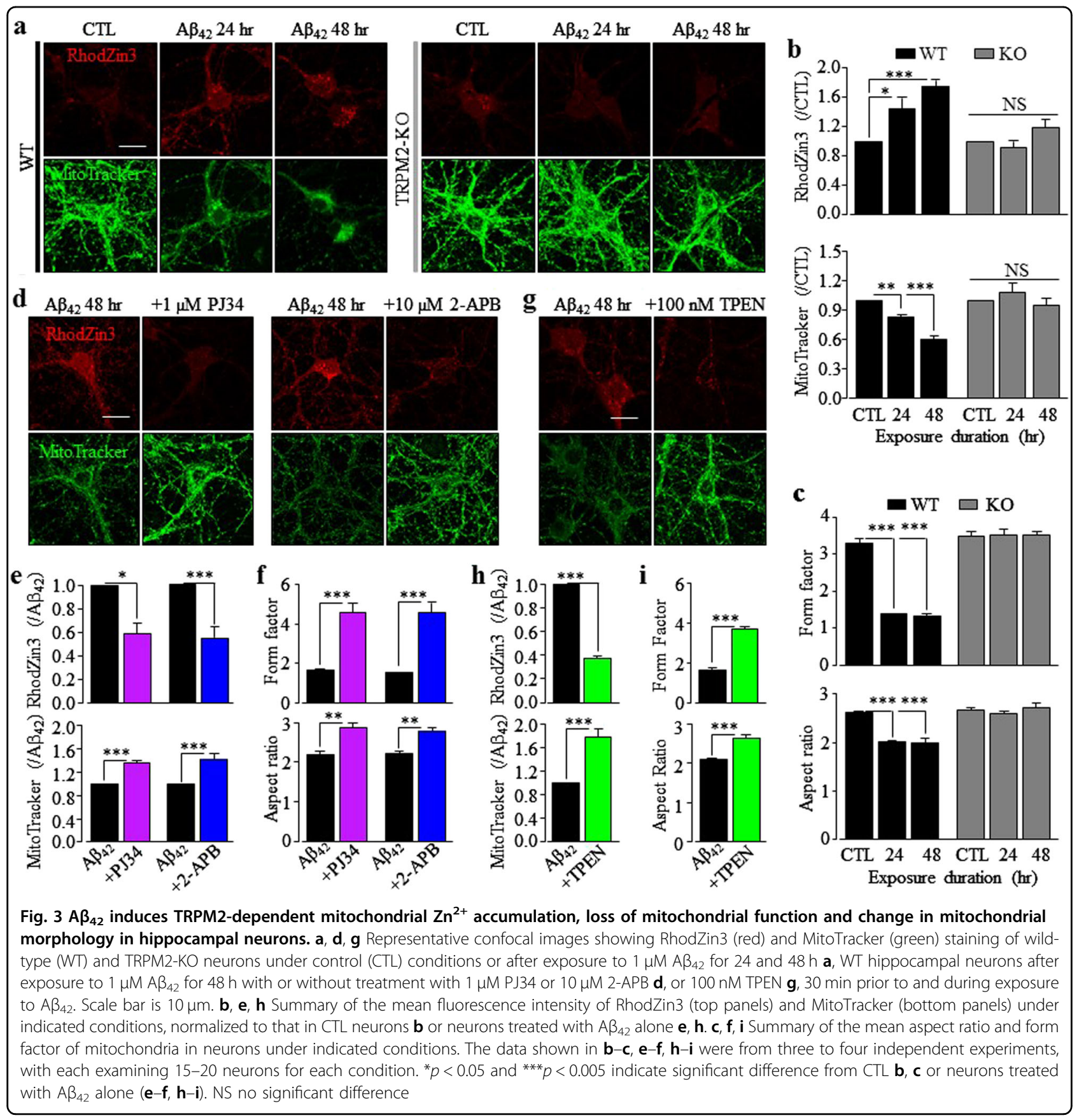

TRPM2 in $A \beta_{42}$-induced mitochondrial $\mathrm{Zn}^{2+}$ accumulation, loss of mitochondria function, change in mitochondrial morphology, and mitochondrial generation of ROS

Increasing evidence shows loss of mitochondria or mitochondrial function in neurons in the close vicinity or contact with $A \beta$-laden senile plaque ${ }^{5,37-39}$. As introduced above, $\mathrm{Zn}^{2+}$ bears an intimate relationship with loss of mitochondrial function and mitochondrial generation of ROS. Therefore, we performed singe-cell imaging to examine mitochondrial $\mathrm{Zn}^{2+}$ accumulation using
RhodZin3 and ensuing effects on the mitochondrial function using MitoTracker Green. Exposure of WT neurons to $A \beta_{42}$ for $24-48 \mathrm{~h}$ stimulated substantial mitochondrial $\mathrm{Zn}^{2+}$ accumulation and also strong reduction in MitoTracker intensity that suggests loss of mitochondrial function (Fig. 3a,b). Consistently, there was a low but significant level of cytochrome-c (Cyt-c) release in WT neurons after exposure to $\mathrm{A} \beta_{42}$ for $24-48 \mathrm{~h}$ detected by immunostaining (supplementary Fig.6). Analysis of the form factor and aspect ratio of 


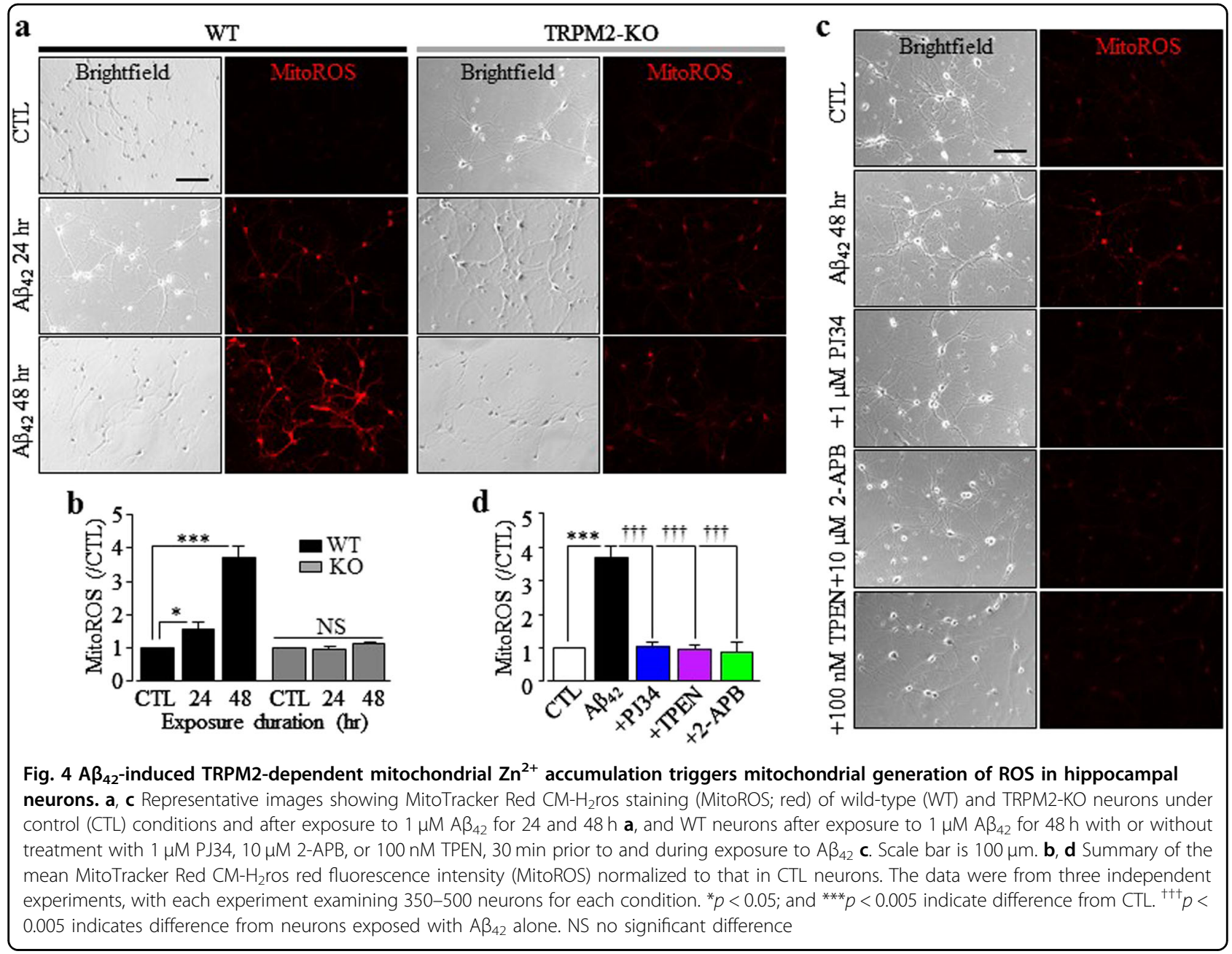

mitochondria reveals salient change in their morphology (Fig .3a,c, supplementary Fig.7 and supplementary Fig.8a). $\mathrm{A} \beta_{42}$-induced mitochondrial $\mathrm{Zn}^{2+}$ accumulation, loss of MitoTracker intensity and change in mitochondrial morphology were abolished by TRPM2-KO (Fig. 3a-c, supplementary Fig.7 and supplementary Fig.8b) and strongly inhibited by treatment with $1 \mu \mathrm{M}$ PJ34 or $10 \mu \mathrm{M}$ 2-APB (Fig. 3d-f; supplementary Fig.8c-d). A $\beta_{42}$-induced mitochondrial effects in WT neurons were also suppressed by treatment with $100 \mathrm{nM}$ TPEN (Fig. 3g-i; supplementary Fig.8e). Taken together, these results show that $A \beta_{42}$-induced TRPM2-dependent mitochondrial $\mathrm{Zn}^{2}$ ${ }^{+}$accumulation causes loss of mitochondrial function and change in mitochondrial morphology.

We next investigated whether $A \beta_{42}$-induced mitochondrial $\mathrm{Zn}^{2+}$ accumulation stimulated generation of ROS and furthermore whether such generation of ROS was also dependent of TRPM2, using MitoTracker Red CM$\mathrm{H}_{2}$ Xros. The mitochondrial ROS level in WT neurons was increased by approximately 1.5 -fold and 4 -fold after exposure to $A \beta_{42}$ for 24 and $48 \mathrm{~h}$, respectively (Fig. $\left.4 \mathrm{a}, \mathrm{b}\right)$.
In contrast, $A \beta_{42}$ induced no mitochondrial generation of ROS in TRPM2-KO neurons (Fig. 4a,b) and in WT neurons treated with $1 \mu \mathrm{M}$ PJ34 or $10 \mu \mathrm{M} 2$-APB (Fig. 4c,d). Similarly, there was no $A \beta_{42}$-induced increase in mitochondrial generation of ROS in WT neurons treated with $100 \mathrm{nM}$ TPEN (Fig. 4c,d). Therefore, these results clearly show that $A \beta_{42}$-induced TRPM2-dependent mitochondrial $\mathrm{Zn}^{2+}$ accumulation stimulates mitochondrial generation of ROS.

TRPM2 in bafilomycin-induced increase in the $\left[\mathrm{Zn}^{2+}\right]_{\mathrm{C}}$ mitochondrial $\mathrm{Zn}^{2+}$ accumulation, and mitochondrial generation of ROS

We hypothesized that $A \beta_{42}$-induced lysosomal dysfunction triggers an increase in the $\left[\mathrm{Zn}^{2+}\right]_{\mathrm{c}}$ and subsequent mitochondrial $\mathrm{Zn}^{2+}$ accumulation. To seek supporting evidence, we returned to bafilomycin and asked whether bafilomycin-induced lysosomal dysfunction gave rise to an increase in the $\left[\mathrm{Zn}^{2+}\right]_{\mathrm{c}}$ and mitochondrial $\mathrm{Zn}^{2+}$ accumulation like $\mathrm{A} \beta_{42}$. Exposure to 100 $\mathrm{nM}$ bafilomycin for $30 \mathrm{~min}$ resulted in a significant 


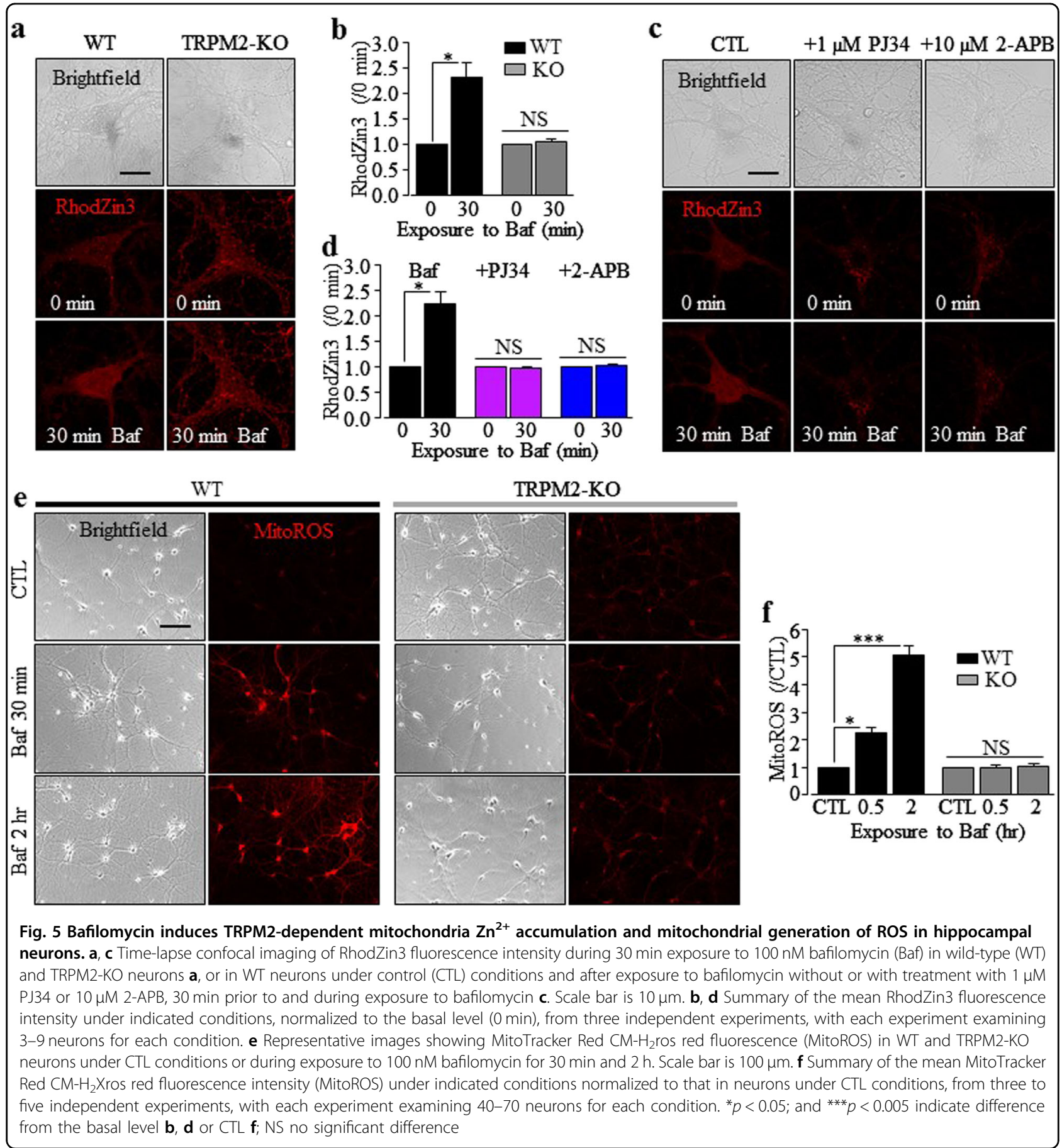

increase in the $\left[\mathrm{Zn}^{2+}\right]_{\mathrm{c}}$ (supplementary Fig.9) and mitochondrial $\mathrm{Zn}^{2+}$ accumulation in WT neurons, which were prevented by TRPM2-KO (Fig. 5a,b; supplementary Fig.9). Bafilomycin-induced mitochondrial $\mathrm{Zn}^{2+}$ accumulation was also prevented by treatment with $1 \mu \mathrm{M}$ PJ34 or $10 \mu \mathrm{M}$ 2-APB (Fig. 5c,d). Furthermore, bafilomycin induced massive mitochondrial generation of ROS in WT neurons, but again not in TRPM2-KO neurons (Fig. 5e,f). These results, together with the above-described results from using $A \beta_{42}$, strongly support the hypothesis that $A \beta_{42^{-}}$ induced lysosomal dysfunction triggers an increase in the $\left[\mathrm{Zn}^{2+}\right]_{\mathrm{c}}$ and subsequent mitochondrial $\mathrm{Zn}^{2+}$ accumulation and mitochondrial generation of ROS in a TRPM2dependent manner.

The strong dependence on TRPM2 of bafilomycin/ $\mathrm{A} \beta_{42}$-induced mitochondrial $\mathrm{Zn}^{2+}$ accumulation and 


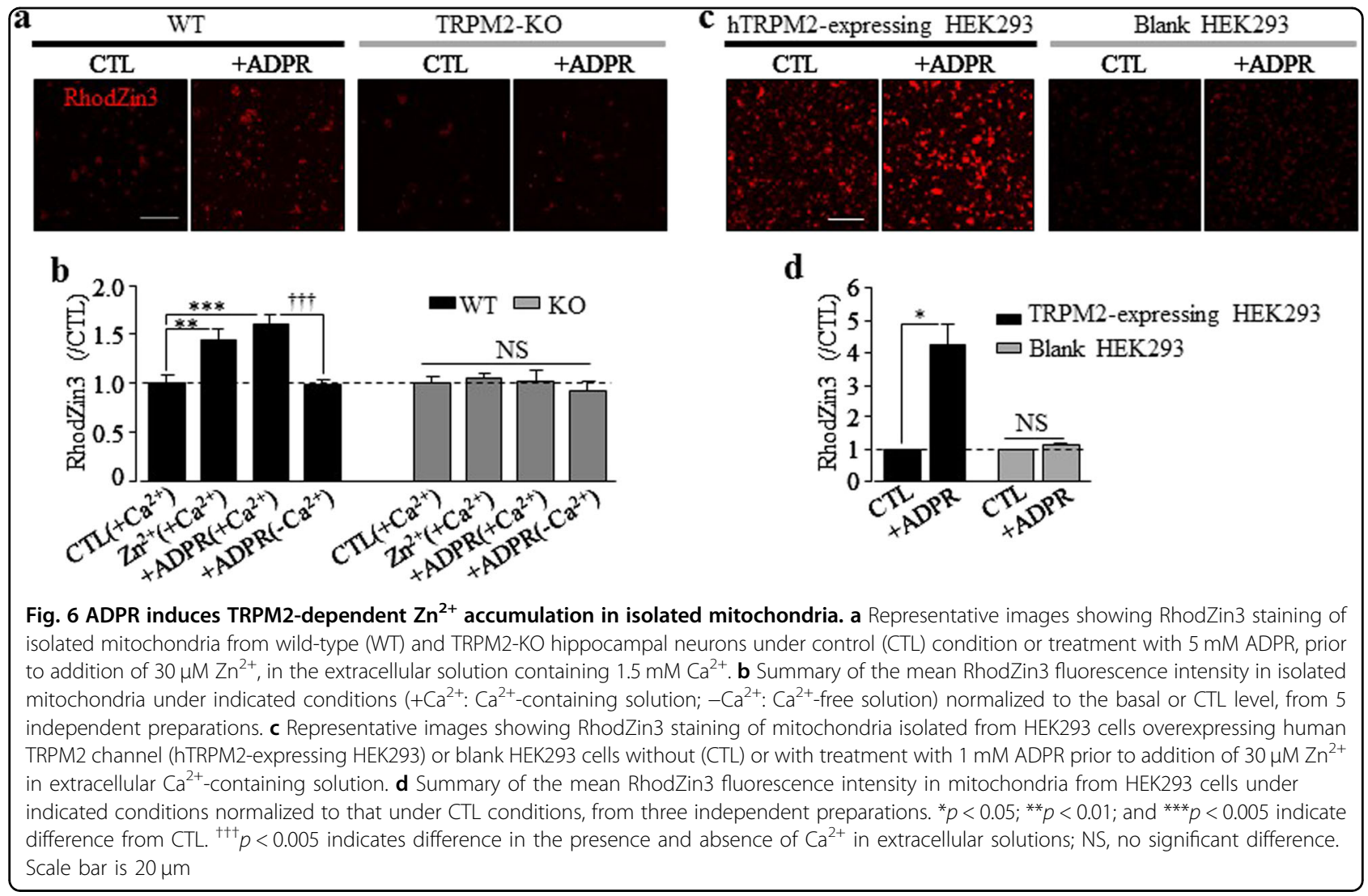

mitochondrial generation of ROS raised an intriguing question regarding the TRPM2 channel in mitochondria. Immunostaining suggests that TRPM2 protein was present intracellularly in hippocampal neurons and exhibited co-localization with MitoTracker (supplementary Fig.10a-b). Western blotting also detected TRPM2 protein in mitochondria isolated from hippocampal neurons (supplementary Fig.10c). To further demonstrate the relevance of mitochondrial expression of TRPM2 to $\mathrm{Zn}^{2+}$ accumulation, we performed RhodZin3 imaging to monitor $\mathrm{Zn}^{2+}$ influx into isolated mitochondria from WT and TRPM2-KO hippocampal neurons. Addition of $\mathrm{Zn}^{2+}$ in the presence of $\mathrm{Ca}^{2+}$ led to a significant increase in the $\mathrm{Zn}^{2+}$ level in mitochondria isolated from WT neurons, which was further elevated by addition of ADPR, the TRPM2 channel specific activator (Fig. 6a,b). In contrast, ADPR induced no increase in the mitochondrial $\mathrm{Zn}^{2+}$ level in the absence of $\mathrm{Ca}^{2+}$ (Fig. 6b). Furthermore, such $\mathrm{Zn}^{2+}$ increases were not observed in mitochondria isolated from TRPM2-KO neurons (Fig. 6a,b). We also examined mitochondria isolated from blank HEK293 cells and HEK293 cells overexpressing the human TRPM2 channel (hTRPM2-expressing HEK293 cells). Western blotting showed a high level of TRPM2 protein in mitochondria from hTRPM2-expressing HEK293 cells and no TRPM2 protein in mitochondria from blank
HEK293 cells (supplementary Fig.10c). Consistently, ADPR induced a robust increase in the $\mathrm{Zn}^{2+}$ level in mitochondria from hTRPM2-expressing, but not blank HEK293 cells (Fig. 6c,d). Collectively, these results are in support of mitochondrial expression of the TRPM2 channel and an important role in mitochondrial $\mathrm{Zn}^{2+}$ accumulation.

PKC and NOX in $A \beta_{42}$-induced hippocampal neurotoxicity and generation of ROS

NOX is an important source of ROS that induce neuronal cell death and protein kinase $\mathrm{C}$ (PKC) is known to activate NOX. Next, we examined whether PKC and NOX were engaged in $A \beta_{42}$-induced neurotoxicity by determining the effects of Gö6976, a PKC inhibitor, apocynin and DPI, two generic NOX inhibitors, and GKT137831, a NOX1/4-selective inhibitor, on $A \beta_{42}$-induced neurotoxicity and generation of ROS. $A \beta_{42}$-induced neurotoxicity was significantly attenuated or prevented by treatment with 10-30 nM Gö6967, 10-30 $\mu \mathrm{M}$ apocynin, $1 \mathrm{nM}$ DPI, or 1-10 $\mathrm{M}$ GKT137831 (Fig. 7a-g). We also showed using DCFH-DA assay that $A \beta_{42}$ induced a salient increase in cellular ROS, which was abolished by treatment with $10 \mathrm{nM}$ Gö6976, $30 \mu \mathrm{M}$ apocynin, $1 \mathrm{nM}$ DPI, or $10 \mu \mathrm{M}$ GKT137831 (Fig. 7h,i). To further investigate the role of PKC/NOX-mediated generation of ROS in $A \beta_{42^{-}}$ 


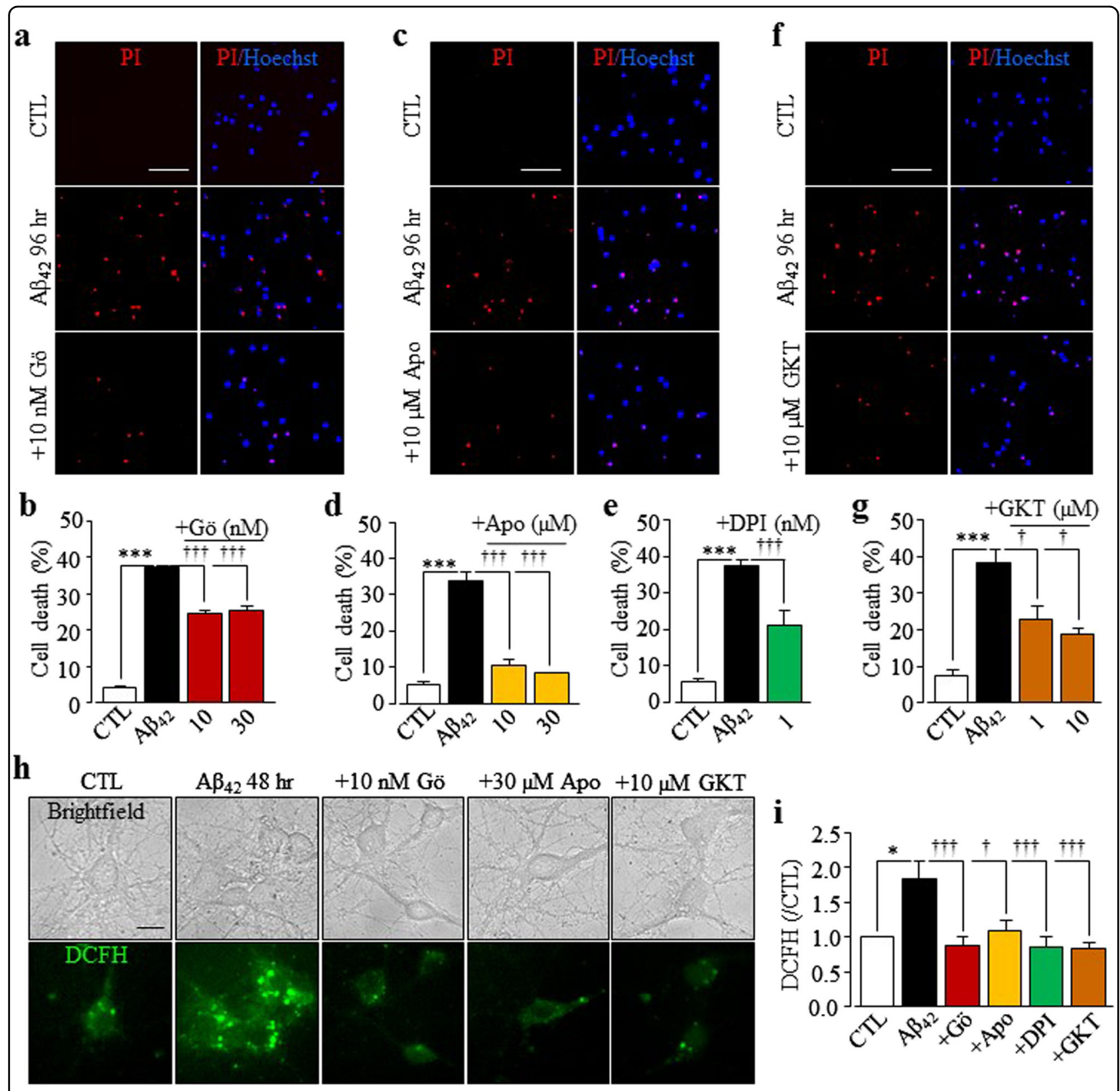

Fig. 7 PKC and NOX inhibitors suppress $A \beta_{42}$-induced neurotoxicity and generation of ROS in hippocampal neurons. $a, c, f$ Representative images showing PI staining of wild-type neurons under control $(C T L)$ conditions or after exposure to $1 \mu \mathrm{M} \mathrm{A} \beta_{42}$ for $48 \mathrm{~h}$ with or without treatment with $10 \mathrm{nM}$ Gö6976 (Gö, a), $30 \mu \mathrm{M}$ apocynin (Apo, b), or $10 \mu \mathrm{M}$ GKT137831 (GKT, c), 30 min prior to and during exposure to A $\beta_{42}$. Each consists of PI images showing dead neurons and merged images of Hoechst (blue)/PI staining showing all and dead neurons. Scale bar is $100 \mu \mathrm{m}$. b, d, e, $\mathbf{g}$ Summary of the mean percentage of Pl-positive neurons under indicated conditions, from three to five independent experiment with each examining 400-600 neurons for each condition. ${ }^{* * *} p<0.05$ indicates difference from neurons under CTL conditions. ${ }^{\dagger} p<0.05$ and ${ }^{\mathrm{tt}+} p<0.005$ indicate difference from neurons exposed to $A \beta_{42}$ alone. $\mathbf{h}$ Representative images showing DCFH fluorescence in neurons under CTL and after exposure to $1 \mu \mathrm{M} \mathrm{A} \beta_{42}$ for $48 \mathrm{~h}$ with or without treatment with $10 \mathrm{nM}$ Gö6976 (Gö), $30 \mu \mathrm{M}$ apocynin (Apo), $1 \mathrm{nM}$ DPI, or $10 \mu \mathrm{M}$ GKT137831 (GKT), 30 min prior to and during exposure to $A \beta_{42}$. Scale bar is $10 \mu \mathrm{m}$. i Summary of the mean DCFH fluorescence intensity in neurons under indicated conditions normalized to the basal or CTL level, from four independent experiments with each experiment examining 10-15 neurons for each conditions. ${ }^{*} p<0.05$ indicates difference from $\mathrm{CTL} .{ }^{\dagger} p<0.05$; and ${ }^{\mathrm{t \dagger}} p<0.005$ indicate difference from that in neurons exposed with $\mathrm{A} \beta_{42}$ alone

induced neurotoxicity, we also examined the effects of inhibiting PKC and NOX on $\mathrm{A} \beta_{42}$-induced increase in the $\left[\mathrm{Zn}^{2+}\right]_{\mathrm{c}}$, lysosomal dysfunction, mitochondrial $\mathrm{Zn}^{2+}$ accumulation, and subsequent effects on mitochondrial function. Treatment with $10 \mathrm{nM}$ Gö6976 strongly inhibited $\mathrm{A} \beta_{42}$-induced increase in the $\left[\mathrm{Zn}^{2+}\right]_{\mathrm{c}}$ (Fig. 8a,b), 


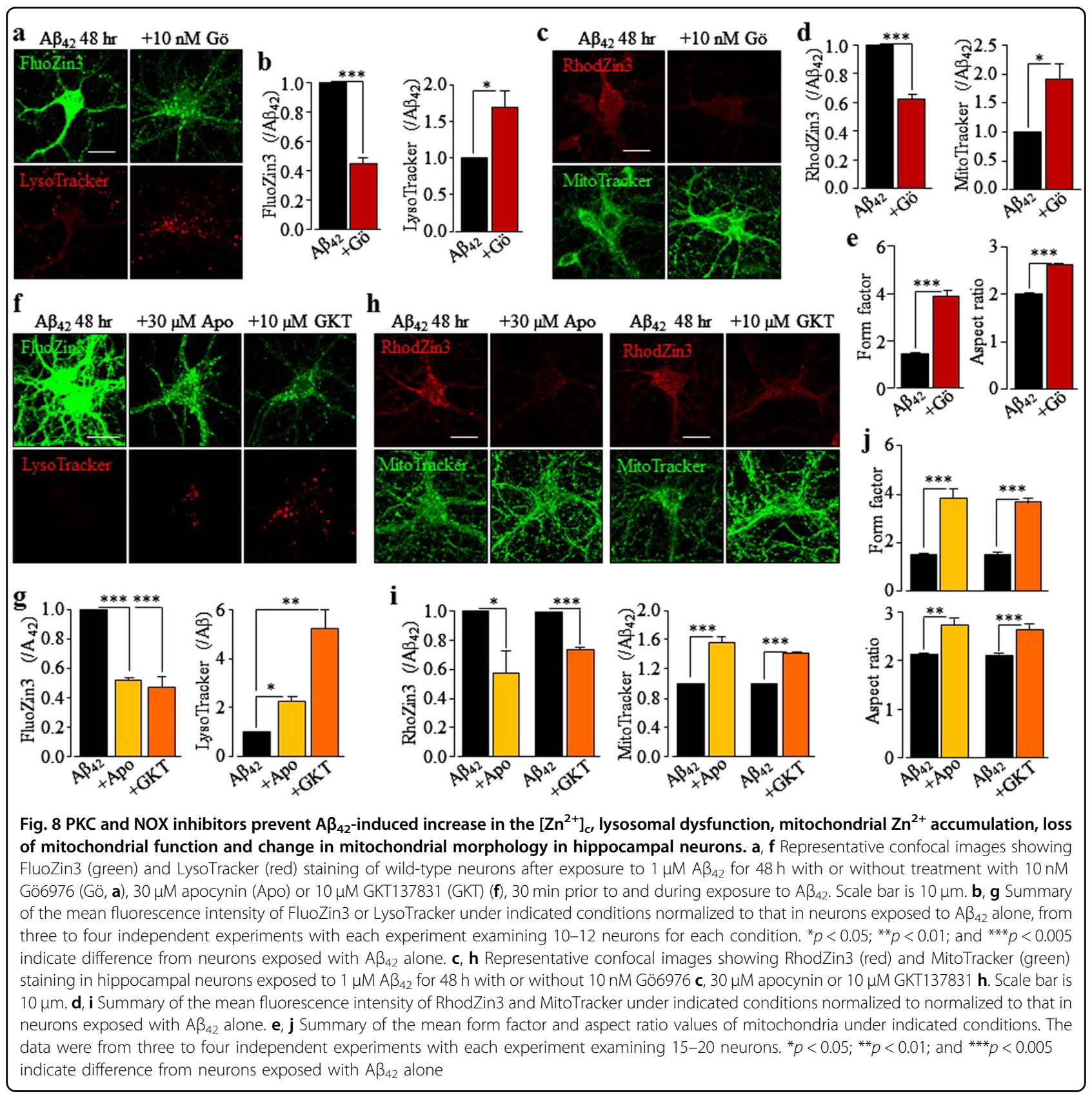

lysosomal dysfunction (Fig. 8a,b), mitochondrial $\mathrm{Zn}^{2+}$ accumulation (Fig. 8c,d), loss of MitoTracker intensity (Fig. 8c,d), and change in mitochondrial morphology (Fig. 8c,e; supplemental Fig.11a). Similarly, treatment with 30 $\mu \mathrm{M}$ apocynin or $10 \mu \mathrm{M}$ GKT137831 resulted in a strong inhibition of $\mathrm{A} \beta_{42}$-induced increase in the $\left[\mathrm{Zn}^{2+}\right]_{\mathrm{c}}$ (Fig. 8f, g), lysosomal dysfunction (Fig. 8f,g), mitochondrial $\mathrm{Zn}^{2+}$ accumulation (Fig. 8h,i), loss of MitoTracker intensity (Fig. 8h,i), and change in mitochondrial morphology (Fig. 8h,j; supplementary Fig.11b-c). Overall, these results provide strong evidence to suggest that PKC and NOX play an important role in $\mathrm{A} \beta_{42}$-induced generation of ROS that lead to loss of lysosomal and mitochondrial functions and neurotoxicity.

\section{MEK/ERK in $A \beta_{42}$-induced hippocampal neurotoxicity}

Activation of PARP-1 is long known as an important factor in ROS-induced neurotoxicity ${ }^{40}$. As introduced above, PARP-1-dependent generation of ADPR represents a major mechanism in ROS-induced TRPM2 channel activation and subsequent cell death ${ }^{20}$. A recent study has reported that ROS stimulates PARP-1 activation via mitogen-activated protein kinase (MEK) and downstream extracellular signal-regulated kinase (ERK) ${ }^{41}$. Therefore, 

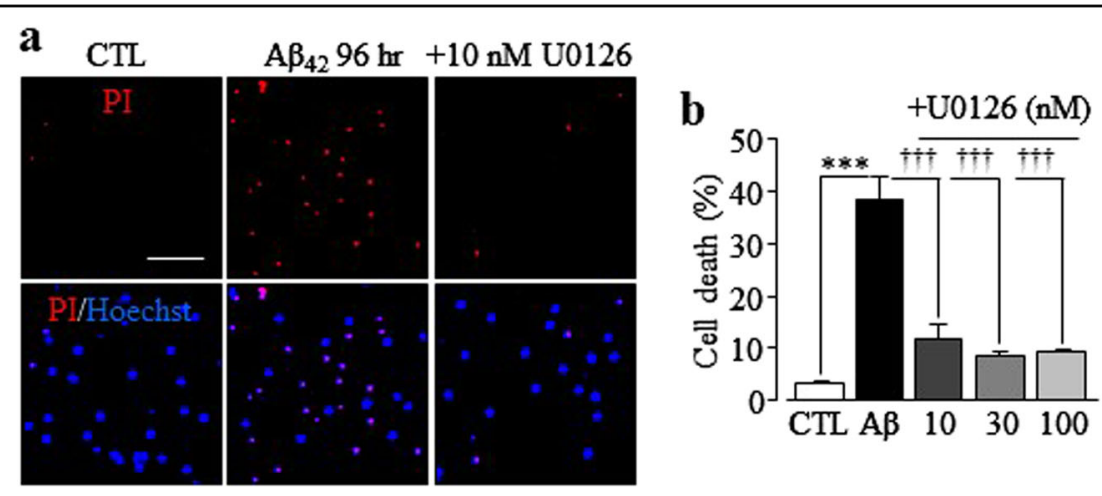

Fig. 9 MEK/ERK inhibitor prevents $\mathbf{A} \boldsymbol{\beta}_{42}$-induced hippocampal neurotoxicity. a Representative images showing PI staining of wild-type neurons

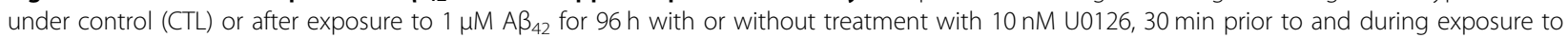
$\mathrm{A} \beta_{42}$. Each panel consists of Pl-staining image (red) showing dead neurons and merged Hoechst (blue)/PI staining showing all and dead neurons. Scale bar is $100 \mu \mathrm{m}$. b Summary of the mean percentage of PI-positive neurons under indicated conditions, from three independent experiments with each examining 400-650 neurons for each condition. ${ }^{* * *} p<0.005$ indicates difference from neurons under control conditions. ${ }^{\mathrm{t+ \dagger}} p<0.005$ indicates difference from neurons exposed with $1 \mu \mathrm{M} \mathrm{A} \beta_{42}$ alone

we finally examined the role of MEK/ERK in $A \beta_{42^{-}}$ induced neurotoxicity. $A \beta_{42}$-induced neurotoxicity was almost completely prevented by treatment with $10 \mathrm{nM}$ U0126, a MEK/ERK inhibitor (Fig. 9a,b), thus suggesting critical engagement of MEK/ERK in $\mathrm{A} \beta_{42}$-induced neurotoxicity.

\section{Discussion}

The present study reveals multiple mechanisms that form a positive feedback loop to drive $A \beta_{42}$-induced TRPM2-dependent hippocampal neurotoxicity (Fig. 10). Our findings provide novel and mechanistic insights into the causative relationship of TRPM2 channel with AD.

Consistently with $A \beta$-induced oxidative stress and TRPM2 as an oxidative stress-sensitive channel, recent studies describe distinctive cellular mechanisms by which A $\beta$-induced TRPM2 channel activation contributes to $\mathrm{AD}$, including neurotoxicity ${ }^{32}$, neurovascular dysfunction $^{42}$, and neuroinflammation ${ }^{32,43}$. Here we provide evidence to show a vital role for the TRPM2 channel in $\mathrm{A} \beta_{42^{-}}$ induced hippocampal neurotoxicity (Fig. 1). $\mathrm{Ca}^{2+}$ is known as an intracellular signal that is important for diverse cell functions, including cell death, and TRPM2 channel has been shown to play a role in ROS-induced $\mathrm{Ca}^{2+}$ signaling ${ }^{15,44,45}$. ROS-induced TRPM2-mediated cortical neuronal death was attenuated in extracellular $\mathrm{Ca}^{2+}$-free solution ${ }^{25}$. Although previous studies showed cell surface expression of the TRPM2 channel on hippocampal pyramidal neurons ${ }^{30,46}$, there was no measurable increase in the $\left[\mathrm{Ca}^{2+}\right]_{\mathrm{C}}$ following 24-48 $\mathrm{h}$ exposure to $\mathrm{A} \beta_{42}$ in our hippocampal neuronal preparations (supplementary Fig.12). Increasing evidence from recent studies examining hippocampal pyramidal neurons ${ }^{30}$, pancreatic $\beta$-cells ${ }^{35}$, and endothelial cells ${ }^{36}$ supports an important role of TRPM2-dependent increase in the $\left[\mathrm{Zn}^{2+}\right]_{\mathrm{c}}$ in
ROS-induced cell death. Here we showed that $A \beta_{42^{-}}$ induced hippocampal neurotoxicity was almost completely prevented by $100 \mathrm{nM}$ TPEN acting as a selective $\mathrm{Zn}^{2+}$ chelator $^{34}$ (Fig. 1d) as well as by TRPM2-KO or inhibition of the TRPM2 channel (Fig. 2a-d). Taken together, our results support that TRPM2-dependent increase in the $\left[\mathrm{Zn}^{2+}\right]_{\mathrm{c}}$ is critical in $\mathrm{A} \beta_{42}$-induced neurotoxicity.

$\mathrm{Zn}^{2+}$ is of particular abundance in hippocampal neurons and known to accumulate in degenerating neurons after ischemia or seizure ${ }^{34,47}$. Within the cytosol, $\mathrm{Zn}^{2+}$ is buffered by metallothioneins ${ }^{12,14}$ or stored in lysosomes and other intracellular organelles ${ }^{13,35,48}$. We found that $\mathrm{Zn}^{2+}$ in hippocampal neurons was mainly located in lysosome (supplementary Fig.4). In addition to a salient increase in the $\left[\mathrm{Zn}^{2+}\right]_{\mathrm{c}}, \mathrm{A} \beta_{42}$ elicited loss of lysosomal function evidenced by significant reduction in LysoTracker and AO intensity (Fig. 2a,b and supplementary Fig.5). This is consistent with that $A \beta_{42}$ induces generation of ROS, as discussed below, and that ROS causes lysosomal dysfunction ${ }^{13}$ in hippocampal neurons. Taken together, these observations lead us to hypothesize that lysosomal dysfunction results in, at least in part, lysosomal $\mathrm{Zn}^{2+}$ release. This notion is supported by the observation that bafilomycin-induced lysosomal dysfunction also increased the $\left[\mathrm{Zn}^{2+}\right]_{\mathrm{c}}$ (supplementary Fig.9). In addition, bafilomycin-induced increase in the $\left[\mathrm{Zn}^{2+}\right]_{\mathrm{c}}$ was prevented by TRPM2-KO (supplementary Fig.8), indicating that lysosomal $\mathrm{Zn}^{2+}$ release is TRPM2-dependent. It has been proposed that lysosomal TRPM2-mediated $\mathrm{Zn}^{2+}$ release contributes to ROS-induced increase in the $\left[\mathrm{Zn}^{2}\right.$ $\left.{ }^{+}\right]_{c}$ and cell death in pancreatic $\beta$-cells ${ }^{35}$. However, it remains challenging to demonstrate whether or not TRPM2 is a $\mathrm{Zn}^{2+}$-permeable channel, due to the potent inhibition of TRPM2 channel by extracellular $\mathrm{Zn}^{2+}$ at 


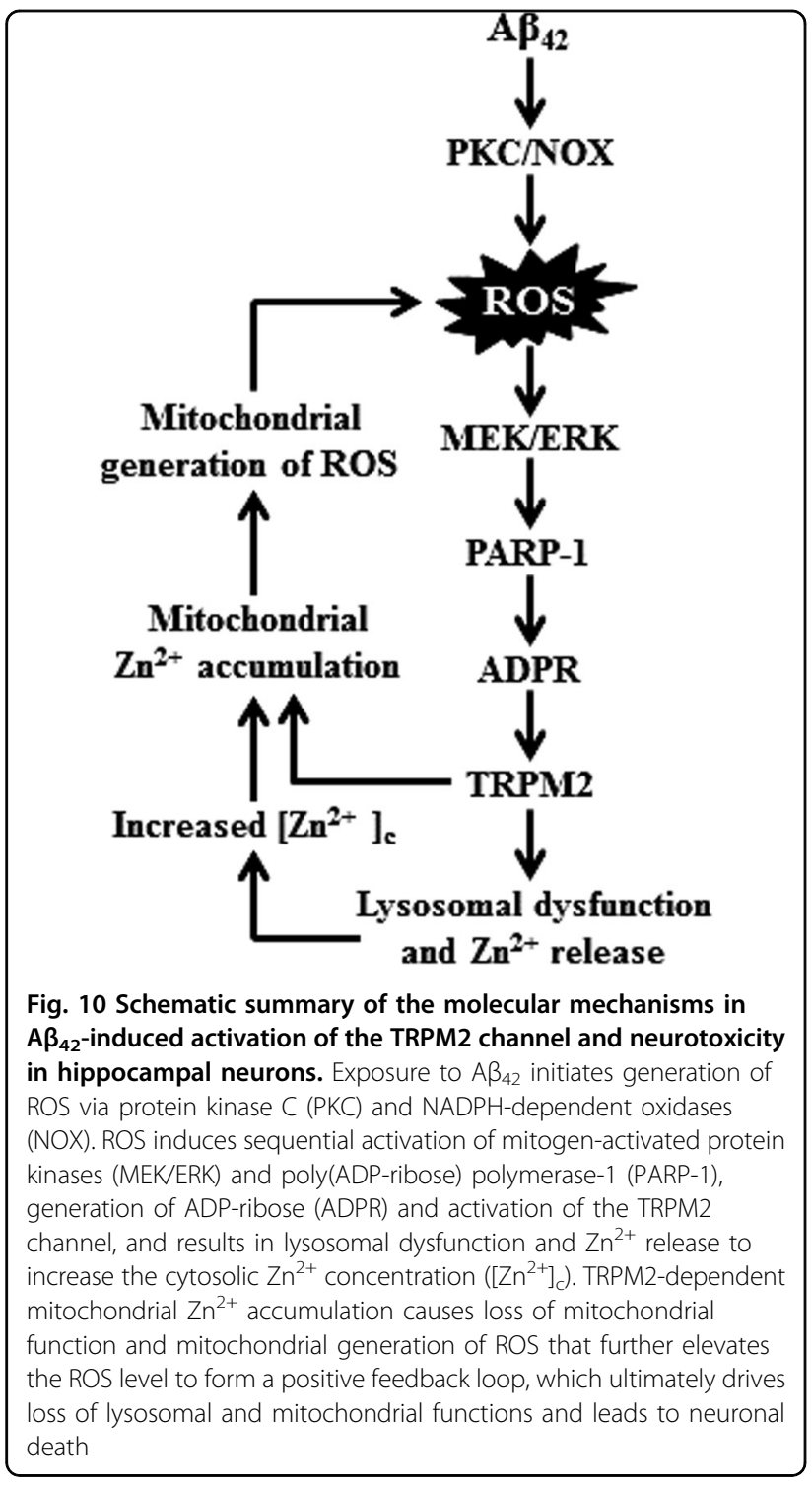

high micromolar concentrations ${ }^{49}$. Regardless, further studies are required to better understand the mechanisms responsible for TRPM2-dependent lysosomal $\mathrm{Zn}^{2+}$ release in hippocampal neurons. Of notice, $A \beta_{42}$-elicited lysosomal dysfunction in hippocampal neurons was prevented by TPEN (Fig. 2c-f) as well as TRPM2-KO or inhibition of the TRPM2 channel (Fig. 2a-d). These results suggest that TRPM2-dependent increase in the $\left[\mathrm{Zn}^{2+}\right]_{\mathrm{c}}$ has a reciprocal effect on lysosomal function.

The present study showed that $\mathrm{A} \beta_{42}$ induced considerable mitochondrial $\mathrm{Zn}^{2+}$ accumulation in hippocampal neurons (Fig. 3a,b). In remarkable resemblance with $A \beta_{42}$, exposure to bafilomycin led to mitochondrial $\mathrm{Zn}^{2+}$ accumulation. Strikingly, the mitochondrial $\mathrm{Zn}^{2+}$ accumulation induced by both agents was prevented by TPEN (Fig. 3g-i) as well as by TRPM2-KO (Figs. 3a,b and $5 \mathrm{a}-\mathrm{d}$ ) or inhibition of the TRPM2 channel (Fig. 3d-f).
Taken together, these results support the notion that lysosomal dysfunction and accompanying $\mathrm{Zn}^{2+}$ release give rise to mitochondrial $\mathrm{Zn}^{2+}$ accumulation. The finding that bafilomycin-induced mitochondrial $\mathrm{Zn}^{2+}$ accumulation was strongly dependent of the TRPM2 channel raised an intriguing question towards the TRPM2 channel in mitochondrial $\mathrm{Zn}^{2+}$ accumulation. Both immunostaining and western blotting suggest mitochondrial location of TRPM2 in hippocampal neurons (supplementary Fig.10). Consistently, ADPR stimulated $\mathrm{Zn}^{2+}$ accumulation in mitochondria isolated from WT but not TRPM2KO hippocampal neurons (Fig. 6a,b). There was no ADPR-induced $\mathrm{Zn}^{2+}$ accumulation in isolated mitochondria in the absence of $\mathrm{Ca}^{2+}$ (Fig. 6b), consistent with $\mathrm{Ca}^{2+}$ being critical in ADPR-induced TRPM2 channel activation $^{50,51}$, particularly in hippocampal neurons ${ }^{30,46}$. Similar findings were made regarding mitochondrial localization of TRPM2 (supplementary Fig.10c) and ADPR-induced $\mathrm{Zn}^{2+}$ accumulation in mitochondria isolated from HEK293 cells overexpressing the hTRPM2 channel, but not from blank HEK293 cells (Fig. 6c,d). Collectively, these results support the notion that the TRPM2 channel is located in mitochondria and plays an important role in mitochondrial $\mathrm{Zn}^{2+}$ accumulation. A precedent was made by a previous study showing involvement of the TRPC3 channel, another member of the TRP superfamily, in mitochondrial $\mathrm{Ca}^{2+}$ homeostasis ${ }^{52}$. However, as discussed above, it remains uncertain whether the TRPM2 channel permeates $\mathrm{Zn}^{2+}$. Further investigations are thus required to elucidate $\mathrm{A} \beta_{42}$-induced activation of the mitochondrial TRPM2 channel and associated mechanisms in mediating mitochondrial $\mathrm{Zn}^{2+}$ accumulation.

We also observed that $A \beta_{42}$ induced strong loss of MitoTracker fluorescence (Fig. 3a,b) and measurable release of Cyt-c (supplementary Fig.6), suggesting $A \beta_{42^{-}}$ induced loss of mitochondrial function. This is further supported by the finding that $A \beta_{42}$-induced mitochondrial generation of ROS (Fig. 4a). Moreover, $A \beta_{42}$ induced salient change in mitochondrial morphology (Fig. 3a-c), indicating altered mitochondrial dynamics and further studies are required to better understand the implication to mitochondrial function and $A \beta_{42}$-induced neurotoxicity. Nonetheless, all these $A \beta_{42}$-induced mitochondrial effects clearly depend on the TRPM2 channel, as they were prevented by TRPM2-KO or inhibition of the TRPM2 channel as well as by TPEN (Fig. 3d-i). These results strongly support the causative relationship of rising $\left[\mathrm{Zn}^{2+}\right]_{\mathrm{c}}$ with loss of mitochondrial function and generation of ROS reported by earlier studies ${ }^{14,53}$. Furthermore, these results provide clear evidence for the first time to show a critical role for the TRPM2 channel or TRPM2-dependent mitochondrial $\mathrm{Zn}^{2+}$ accumulation in $\mathrm{A} \beta_{42}$-induced loss of mitochondrial function and 
mitochondrial generation of ROS. We propose that mitochondrial generation of ROS acts as a positive feedback in $\mathrm{A} \beta_{42}$-induced hippocampal neurotoxicity (Fig. 10).

It is well-known that NOX-mediated generation of ROS plays a crucial role in neurotoxicity implicated in ischemic stroke and $\mathrm{AD}^{10,11,54}$. As shown here, $\mathrm{A} \beta_{42}$-induced neurotoxicity (Fig. 7c-g) and cellular oxidative stress (Fig. $7 \mathrm{~h}$,i) were strongly suppressed or abolished by apocynin, DPI, or GKT137831, supporting a role of NOX, particularly NOX1 and/or NOX4, in $\mathrm{A} \beta_{42}$-induced generation of ROS, as reported in recent studies in hippocampal neuronal death following stroke $\mathrm{e}^{54-56}$. Notably, $\mathrm{A} \beta_{42}$-induced neurotoxicity (Fig. 7a,b) and oxidative stress (Fig. 7h,i) were inhibited by Gö6976, suggesting a role for PKC in $\mathrm{A} \beta_{42}$-induced activation of NOX. Furthermore, $A \beta_{42^{-}}$ induced lysosomal dysfunction and increase in the $\left[\mathrm{Zn}^{2}\right.$ $\left.{ }^{+}\right]_{\mathrm{c}}$, mitochondrial $\mathrm{Zn}^{2+}$ accumulation, loss of mitochondrial function, and change in mitochondrial morphology (Fig. 8; supplementary Fig.11) were largely reversed by inhibition of NOX. These results indicate that activation of NOX is an important mechanism that likely initiates $A \beta_{42}$-induced generation of ROS, which subsequently induces activation of the PARP-1 and TRPM2 channel, lysosomal dysfunction and $\mathrm{Zn}^{2+}$ release, an increase in the $\left[\mathrm{Zn}^{2+}\right]_{\mathrm{c}}$, and mitochondrial $\mathrm{Zn}^{2+}$ accumulation (Fig. 10).

It is well-documented that PARP-1 is critical in ROSinduced TRPM2 channel activation and cell death in various cell types, including $A \beta_{42}$-induced neuronal death $^{24}$. As recently shown, ROS stimulates PARP-1 via MEK/ERK ${ }^{41}$, and ERK is engaged in PARP-1 activation and oligodendrocyte death induced by transient ischemia ${ }^{57}$. Here, we showed that $A \beta_{42}$-induced neurotoxicity in hippocampal neurons was completely prevented by U0126 (Fig. 9a,b), indicating that MEK/ERK is critical in $\mathrm{A} \beta_{42}$-induced PARP-1 activation in hippocampal neurons (Fig. 10).

In summary, this study reveals multiple mechanisms, including PKC/NOX-mediated generation of ROS, activation of MEK/ERK and PARP-1, lysosomal dysfunction and $\mathrm{Zn}^{2+}$ release, mitochondrial $\mathrm{Zn}^{2+}$ accumulation, loss of mitochondrial function, and mitochondrial generation of ROS, that are critically engaged in forming a positive feedback loop that drives $A \beta_{42}$-induced TRPM2 channel activation and loss of lysosomal and mitochondrial function, which ultimately leads to hippocampal neurotoxicity. These findings provide novel and mechanistic insights into $\mathrm{AD}$ pathogenesis.

\section{Materials and Methods Reagents}

All reagents, including 2-APB (2-aminoethoxydiphenyl borate), DPQ (3,4-dihydro-5[4-(1-piperindinyl)butoxy]-1
(2 H)-isoquinoline), TPEN (N,N,N',N'-tetrakis(2-pyridylmethyl)ethylenediamine), DPI (diphenyleneiodonium), and DCFH-DA ( $2^{\prime}, 7^{\prime}$-dichloro-dihydro-fluorescein diacetate), were commercially purchased from Sigma unless specifically indicated. All stock solutions including the $A \beta_{42}$ and $A \beta_{42-1}$ peptides were prepared following the manufacturers' instructions, aliquoted and kept at $-20^{\circ} \mathrm{C}$.

\section{Primary hippocampal neuron culture preparation}

All experiments and experimental protocols involving mice were approved by the University of Leeds Ethical Review Committee and performed in accordance with the University of Leeds guidelines and procedure and conforming to the UK Home Office rules and regulations. Generation of transgenic TRPM2-KO C57BL/6 mice was detailed previously ${ }^{58}$. Primary hippocampal neurons were prepared from early postnatal (P0-P1) WT C57BL/6 mice and TRPM2-KO mice using the protocols described previously $^{59}$. In brief, hippocampal tissues were dissected from the whole brain and collected into a $3.5-\mathrm{cm}$ petridish containing ice-cold Hank's balanced salt solutions (HBSS, Invitrogen). Tissues were incubated in $2 \mathrm{ml}$ of $0.125 \%$ trypsin-ethylenediaminetetraacetic acid (trypsinEDTA) solutions (Invitrogen) in $37^{\circ} \mathrm{C}$ for $15 \mathrm{~min}$, stirred up by gentle swirling every $5 \mathrm{~min}$. After trypsin-EDTA solutions were removed, the tissues were transferred in 2 ml of Dulbecco's Modified Eagle Medium: Nutrient Mixture F-12 (DMEM/F12) containing 10\% horse serum (Thermo Scientific) and carefully triturated by pipetting 50 times. The dissociated tissues were filtered into a $50-\mathrm{ml}$ Falcon tube through a 70- $\mu$ m nylon cell strainer (Fisher Scientific) to obtain single-cell suspension. Cell suspension was centrifuged at $100 \times g$ for $5 \mathrm{~min}$, and cell pellets were re-suspended in fresh DMEM/F12 medium supplemented with $10 \%$ horse serum (Thermo Scientific), 5 unit/ $\mathrm{ml}$ penicillin and $50 \mu \mathrm{g} / \mathrm{ml}$ streptomycin. Single cells were seeded in poly-L-lysine pre-coated 24-well plate or glassbottomed petri-dish at a density of 100 cells $/ \mathrm{mm}^{2}$ in DMEM/F12 medium supplemented with $10 \%$ horse serum (Thermo Scientific), which was replaced after $4 \mathrm{~h}$ with $\mathrm{Neurobasal}^{\circ}$ medium supplemented with $2 \%$ serum free B27 supplement, $0.5 \mathrm{mM}$ L-glutamine, $5 \mathrm{unit} / \mathrm{ml}$ penicillin and $50 \mu \mathrm{g} / \mathrm{ml}$ streptomycin. Cytosine $\beta$-D-arabinofuranoside was added at the final concentration of 1 $\mu \mathrm{M}$ after 2 days to inhibit microglial growth. Cells were cultured $14-16$ days in vitro at $37^{\circ} \mathrm{C}$ under $5 \% \mathrm{CO}_{2}$ humidified conditions, with the medium changed twice a week. Immunostaining with an antibody recognizing microtubule associated protein-2 (MAP-2), a neuronspecific protein, showed $98 \%$ cells in hippocampal neuronal preparations used in this study were MAP-2 positive. 


\section{Immunocytochemistry}

Neurons were seeded in poly-L-lysine coated coverslips inserted in 24-well plate. After gently rinsed with phosphate buffer saline (PBS), neurons were incubated for $1 \mathrm{~h}$ in Zamboni's fixative solutions, made of $15 \%(\mathrm{v} / \mathrm{v})$ picric acid and 5.5\% (v/v) formaldehyde in PBS. Fixed cells were rinsed with PBS and incubated for $1 \mathrm{~h}$ with blocking solutions, made of $10 \%(\mathrm{v} / \mathrm{v})$ goat serum and $4 \%(\mathrm{v} / \mathrm{v})$ Triton X-100 in PBS. In some experiments, cells were incubated in $50 \mathrm{nM}$ MitoTracker Red CMXRos (Life Technologies) for $30 \mathrm{~min}$ before fixing. Cells were incubated with primary rabbit anti-TRPM2 antibody (1:1000; Bethyl) or mouse anti-Cyt-c antibody (1:100, BD Pharmingen) overnight at $4{ }^{\circ} \mathrm{C}$. Cells were washed in PBS, and incubated with anti-rabbit or anti-mouse IgG secondary antibody conjugated with fluorescein isothiocyanate for 1 $h$. Cells were washed with PBS and rinsed in water before mounted with the SlowFade Gold Antifade reagent (Invitrogen) and kept in $4^{\circ} \mathrm{C}$. Images were captured using an inverted LSM880 confocal microscope with a $\times 63$ objective (Zeiss). ImageJ software (National Institutes of Health, USA) was used for image analysis of fluorescent intensity.

\section{PI-staining assays}

Neuronal death was examined using propidium iodide (PI) staining. In brief, following exposure to $A \beta_{42}$ or $A \beta_{42-}$ 1 (ChinaPeptides, Shanghai, China) under indicated conditions, neurons in culture medium were further incubated for $30 \mathrm{~min}$ that contained $5 \mu \mathrm{g} / \mathrm{ml}$ PI and $1 \mu \mathrm{M}$ Hoechst 33342 (Cell Signaling Technology). In some experiments, inhibitors were added for $30 \mathrm{~min}$ before and during exposure to $A \beta_{42}$. Images were captured using an EVOS Cell Imaging System (Life Technologies). ImageJ software was used for analysis of neurons stained with PI and Hoechst.

\section{Single-cell confocal imaging}

Neurons seeded in glass-bottomed petri-dish (World Precision Instruments). After the culture medium was removed, neurons were rinsed with standard buffer solution (SBS: $130 \mathrm{mM} \mathrm{NaCl}, 1.5 \mathrm{mM} \mathrm{CaCl}_{2}, 5 \mathrm{mM} \mathrm{KCl}$, $1.2 \mathrm{mM} \mathrm{MgCl}_{2}, 8 \mathrm{mM}$ glucose, $10 \mathrm{mM}$ HEPES, $\mathrm{pH} 7.4$ ) and incubated in SBS containing $1 \mu \mathrm{M}$ Fluo4-AM, $1 \mu \mathrm{M}$ FluoZin3-AM or $3 \mu \mathrm{M}$ RhodZin3-AM (Life Technologies) and $0.1 \%(\mathrm{w} / \mathrm{v})$ pluronic acid at $37^{\circ} \mathrm{C}$ in a tissue culture incubator for $1 \mathrm{~h}$. In some experiments, neurons were kept in SBS containing $25 \mathrm{nM}$ MitoTracker Red CMXRos, $100 \mathrm{nM}$ MitoTracker Green FM, or $1 \mu \mathrm{M}$ LysoTracker Red DND-99 (all from Life Technologies) after removal of FluoZin3 or RhodZin3. Neurons were rinsed with and kept in SBS. Inhibitors were added into SBS at indicated concentrations to test their effects on the cytosolic or mitochondrial $\mathrm{Zn}^{2+}$ as well as lysosomal and mitochondrial functions. For time-lapse recording, images were captured every $5 \mathrm{~min}$ for a total duration of $30 \mathrm{~min}$ after bafilomycin was administrated. Neurons were maintained with SBS before images were captured using an inverted LSM880 confocal microscope with a $\times 63$ objective (Zeiss). Environmental control was applied to maintain $37^{\circ} \mathrm{C}$ and $5 \%$ $\mathrm{CO}_{2}$ during live cell imaging. ImageJ software was used for analysis of fluorescent intensity.

\section{ROS generation}

Mitochondrial ROS generation was measured using MitoTracker Red CM- $\mathrm{H}_{2} \mathrm{Xros}$ (Life Technologies) according to the manufacturer's instructions. Cellular oxidative stress was monitored by DCFH-DA. After exposed to indicated treatments, neurons were incubated in culture medium containing $100 \mathrm{nM}$ MitoTracker Red $\mathrm{CM}-\mathrm{H}_{2} \mathrm{Xros}$ or $3 \mu \mathrm{M}$ DCFH-DA for $30 \mathrm{~min}$ at $37^{\circ} \mathrm{C}$. Cells were washed with and maintained in SBS before images were captured using an EVOS Cell Imaging System. ImageJ software was used for analysis of fluorescent intensity.

\section{Mitochondria isolation and $\mathrm{Zn}^{2+}$ labeling}

Mitochondria were isolated from cultured hippocampal neurons, human embryonic kidney 293 (HEK293) cells, TRPM2-inducible HEK293 cells overexpressing the recombinant human TRPM2 channel (hTRPM2-HEK293 cells $^{60}$, using a Mitochondria Isolation kit (Thermo Scientific) according to the manufacturer's instructions. Isolated mitochondria were suspended with Mitochondria Isolation Reagent $\mathrm{C}$ from the kit and exposed to the indicated treatments and, after centrifugation at 12,000 $\times$ $g$ for $5 \mathrm{~min}$, re-suspended in SBS containing $1 \mu \mathrm{M}$ RhodZin3-AM ${ }^{61}$ with $0.1 \%$ pluronic acid (Life Technologies) and incubated at $37^{\circ} \mathrm{C}$ for $1 \mathrm{~h}$. In some experiments, $\mathrm{Ca}^{2+}$-free SBS supplemented with 0.4 mM EGTA was used. RhodZin3-AM was removed by centrifugation at $12,000 \times g$ for $5 \mathrm{~min}$, and pellets were re-suspended with SBS. The mitochondria suspension was dropped on a glass slide and covered with a rectangular coverslip. Images were captured using an inverted LSM700 confocal microscope with a $\times 63$ oil objective (Zeiss). ImageJ software was used for analysis of fluorescent intensity.

\section{Analysis of lysosomal dysfunction}

Lysosomal dysfunction or lysosomal membrane permeabilization was evaluated by AO staining. After treated under indicated conditions, neurons were stained with 5 $\mu \mathrm{g} / \mathrm{ml} \mathrm{AO}$ at $37^{\circ} \mathrm{C}$ for $15 \mathrm{~min}$. AO-induced red fluorescence were captured using an EVOS Cell Imaging System. Image software was used for analysis of AO red fluorescence intensity.

Western blotting. Mitochondria were isolated from mouse hippocampus and cortex, blank HEK293 cells, 
hTRPM2-expressing HEK293 cells, as described above. Isolated mitochondria were lysed at $4^{\circ} \mathrm{C}$ in radioimmunoprecipitation assay buffer for $30 \mathrm{~min}$. Proteins were separated by sodium dodecyl sulfate-polyacrylamide gel electrophoresis on 10\% separating gels and transferred onto polyvinylidene difluoride membranes. After incubation with the primary rabbit anti-TRPM2 antibody (1:500; Abcam), mouse anti-LAMP-1 antibody (1:1000; Genetex) or mouse anti-Cyt-c antibody (1:500; BD Pharmingen), and the secondary anti-rabbit or anti-mouse antibodies conjugated to horseradish peroxidase. Proteins were visualized using SuperSignal West Pico PLUS Chemiluminescent Substrates (ThermoFisher).

\section{Data analysis}

Neuronal death was expressed by the number of PIpositive neurons as percentage of all neurons in the same areas identified by Hoechst staining. Co-localization of two fluorescent signals was quantified by Pearson's correlation coefficient that varies between 0 and 1 , being no and total positive correlation, as described previously ${ }^{62}$. The morphology of mitochondria was characterized by computer-assisted analysis of the aspect ratio and form factor values as described previously ${ }^{63}$. Data are presented as mean \pm standard error mean (S.E.M.). Statistical significance analysis was conducted using analysis of variance with post hoc Tukey test, with significance at the level of $p<0.05$.

\section{Acknowledgments}

X.L. is a recipient of University of Leeds/Chinese Scholar Council PhD scholarship. The work was supported in part by National Natural Science Foundation of China (31471118), Department of Education of Henan Province (16IRTSTHN020) and Alzheimer's Research Trust (ART/PPG2009A/2) to L.-H.J.

\section{Author contributions}

L.-H.J. conceived the project. L.-H.J. and X.L. designed the experiments. X.L. performed the experiments and analyzed the data. L.H.J. and X.L. wrote and revised the manuscript.

\section{Conflict of interest}

The authors declare that they have no conflict of interest.

\section{Publisher's note}

Springer Nature remains neutral with regard to jurisdictional claims in published maps and institutional affiliations.

Supplementary Information accompanies this paper at (https://doi.org/ 10.1038/s41419-018-0270-1).

Received: 16 January 2017 Revised: 1 December 2017 Accepted: 27 December 2017

Published online: 07 February 2018

\footnotetext{
References

1. Haass, C. \& Selkoe, D. J. Cellular processing of beta-amyloid precursor protein
} and the genesis of amyloid beta-peptide. Cell 75, 1039-1042 (1993).
2. Mucke, L. \& Selkoe, D. J. Neurotoxicity of amyloid $\beta$-protein: synaptic and network dysfunction. Cold Spring Harb. Perspect. Med 2, a006338 (2012).

3. De Felice, F. G. et al. A $\beta$ oligomers induce neuronal oxidative stress through an $\mathrm{N}$-methyl-d-aspartate receptor-dependent mechanism that is blocked by the Alzheimer drug memantine. J. Biol. Chem. 282, 11590-11601 (2007).

4. McLean, C. A. et al. Soluble pool of Abeta amyloid as a determinant of severity of neurodegeneration in Alzheimer's disease. Ann. Neurol. 46, 860-866 (1999).

5. Wang, X. et al. Oxidative stress and mitochondrial dysfunction in Alzheimer's disease. Biochim. Biophy. Acta 1842, 1240-1247 (2014).

6. Sensi, S. L., Paoletti, P., Bush, A. I. \& Sekler, I. Zinc in the physiology and pathology of the CNS. Nat. Rev. Neurosci. 10, 780-791 (2009).

7. Shuttleworth, C. W. \& Weiss, J. H. Zinc: new clues to diverse roles in brain ischemia. Trends Pharmacol. Sci. 32, 480-486 (2011)

8. Brandes, R. P., Weissmann, N. \& Schroder, K. Nox family NADPH oxidases: Molecular mechanisms of activation. Free Radic. Biol. Med. 76, 208-226 (2014).

9. Jiang, F., Zhang, Y. \& Dusting, G. J. NADPH oxidase-mediated redox signaling: roles in cellular stress response, stress tolerance, and tissue repair. Pharmacol. Rev. 63, 218-242 (2011).

10. Nayernia, Z., Jaquet, V. \& Krause, K. H. New insights on NOX enzymes in the central nervous system. Antioxid. Redox Signal. 20, 2815-2837 (2014).

11. Zekry, D., Epperson, T. K. \& Krause, K. H. A role for NOX NADPH oxidases in Alzheimer's disease and other types of dementia? IUBMB Life 55, 307-313 (2003).

12. Aizenman, E. et al. Induction of neuronal apoptosis by thiol oxidation: putative role of intracellular zinc release. J. Neurochem. 75, 1878-1888 (2000).

13. Hwang, J. J., Lee, S. J., Kim, T. Y., Cho, J. H. \& Koh, J. Y. Zinc and 4-hydroxy-2nonenal mediate lysosomal membrane permeabilization induced by $\mathrm{H}_{2} \mathrm{O} 2$ in cultured hippocampal neurons. J. Neurosci. 28, 3114-3122 (2008).

14. Dineley, K. E., Votyakova, T. V. \& Reynolds, I. J. Zinc inhibition of cellular energy production: implications for mitochondria and neurodegeneration. J. Neurochem. 85, 563-570 (2003).

15. Li, C., Meng, L., Li, X., Li, D. \& Jiang, L. H. Non-NMDAR neuronal $\mathrm{Ca}^{2+}$-permeable channels in delayed neuronal death and as potential therapeutic targets for ischemic brain damage. Expert Opin. Ther. Targets 19, 879-892 (2015).

16. Perraud, A. L. et al. ADP-ribose gating of the calcium-permeable LTRPC2 channel revealed by Nudix motif homology. Nature 411, 595-599 (2001).

17. Sano, Y. et al. Immunocyte $\mathrm{Ca}^{2+}$ influx system mediated by LTRPC2. Science 293, 1327-1330 (2001)

18. Lange, I. et al. TRPM2 functions as a lysosomal $\mathrm{Ca}^{2+}$-release channel in beta cells. Sci. Signal 2, ra23 (2009).

19. Sumoza-Toledo, A. et al. Dendritic cell maturation and chemotaxis is regulated by TRPM2-mediated lysosomal $\mathrm{Ca}^{2+}$ release. FASEB J. 25, 3529-3542 (2011).

20. Jiang, L. H., Yang, W., Zou, J. \& Beech, D. J. TRPM2 channel properties, functions and therapeutic potentials. Expert. Opin. Ther. Targets 14, 973-988 (2010).

21. Sumoza-Toledo, A. \& Penner, R. TRPM2: a multifunctional ion channel for calcium signalling. J. Physiol. 589, 1515-1525 (2011).

22. Hara, Y. et al. LTRPC2 $\mathrm{Ca}^{2+}$-permeable channel activated by changes in redox status confers susceptibility to cell death. Mol. Cell. 9, 163-173 (2002).

23. Miller, B. A. \& Zhang, W. TRP channels as mediators of oxidative stress. Adv. Exp. Med. Biol. 704, 531-544 (2011).

24. Fonfria, E. et al. Amyloid $\beta$-peptide(1-42) and hydrogen peroxide-induced toxicity are mediated by TRPM2 in rat primary striatal cultures. J. Neurochem. 95, 715-723 (2005).

25. Kaneko, S. et al. A critical role of TRPM2 in neuronal cell death by hydrogen peroxide. J. Pharmacol. Sci. 101, 66-76 (2006).

26. Bai, J. Z. \& Lipski, J. Differential expression of TRPM2 and TRPV4 channels and their potential role in oxidative stress-induced cell death in organotypic hippocampal culture. Neurotoxicology 31, 204-214 (2010).

27. Nakayama, S., Vest, R., Traystman, R. J. \& Herson, P. S. Sexually dimorphic response of TRPM2 inhibition following cardiac arrest-induced global cerebral ischemia in mice. J. Mol. Neurosci. 51, 92-98 (2013).

28. Verma, S. et al. TRPM2 channel activation following in vitro ischemia contributes to male hippocampal cell death. Neurosci. Lett. 530, 41-46 (2012).

29. Alim, I., Teves, L., Li, R., Mori, Y. \& Tymianski, M. Modulation of NMDAR subunit expression by TRPM2 channels regulates neuronal vulnerability to ischemic cell death. J. Neurosci. 33, 17264-17277 (2013).

30. Ye, M. et al. TRPM2 channel deficiency prevents delayed cytosolic $\mathrm{Zn}^{2+}$ accumulation and CA1 pyramidal neuronal death after transient global ischemia. Cell Death Dis. 5, e1541 (2014).

31. Sun Y. et al. TRPM2 promotes neurotoxin $\mathrm{MPP}^{+} / \mathrm{MPTP}$-induced cell death. $\mathrm{Mol}$. Neurobiol. https://doi.org/10.1007/s12035-016-0338-9 (2016). 
32. Ostapchenko, V. G. et al. The transient receptor potential melastatin 2 (TRPM2) channel contributes to beta-amyloid oligomer-related neurotoxicity and memory impairment. J. Neurosci. 35, 15157-15169 (2015)

33. Lambert, M. P. et al. Diffusible, nonfibrillar ligands derived from Aß1-42 are potent central nervous system neurotoxins. Proc. Natl Acad. Sci. USA 95, 6448-6453 (1998)

34. Weiss, J. H., Sensi, S. L. \& Koh, J. Y. $Z^{2+}{ }^{2+}$ : a novel ionic mediator of neural injury in brain disease. Trends Pharmacol. Sci. 21, 395-401 (2000).

35. Manna, P. T. et al. TRPM2-mediated intracellular $\mathrm{Zn}^{2+}$ release triggers pancreatic $\beta$-cell death. Biochem. J. 466, 537-546 (2015).

36. Abuarab, N., Munsey, T. S., Jiang, L. H., Li, J. \& Sivaprasadarao, A. High glucose-induced ROS activates TRPM2 to trigger lysosomal membrane permeabilization and $\mathrm{Zn}^{2+}$-mediated mitochondrial fission. Sci. Signal $\mathbf{1 0}$ eaal4161 (2017)

37. Reddy, P. H. et al. Amyloid-beta and mitochondria in aging and Alzheimer's disease: implications for synaptic damage and cognitive decline. J. Alzheimers Dis. 20, S499-S512 (2010).

38. Mossmann, $D$. et al. Amyloid- $\beta$ peptide induces mitochondrial dysfunction by inhibition of preprotein maturation. Cell Metab. 20, 662-669 (2014).

39. Xie, $\mathrm{H}$. et al. Mitochondrial alterations near amyloid plaques in an Alzheimer's disease mouse model. J. Neurosci. 33, 17042-17051 (2013).

40. Yu, S. W., Wang, H., Dawson, T. M. \& Dawson, V. L. Poly(ADP-ribose) polymerase-1 and apoptosis inducing factor in neurotoxicity. Neurobiol. Dis. 14, 303-317 (2003).

41. Akhiani, A. A. et al. Role of the ERK pathway for oxidant-induced parthanatos in human lymphocytes. PLOS ONE 9, e89646 (2014).

42. Park, L. et al. The key role of transient receptor potential melastatin-2 channels in amyloid-beta-induced neurovascular dysfunction. Nat. Commun. 5, 5318 (2014).

43. Syed Mortadza, A. S., Sim, J. A., Neubrand, V. E. \& Jiang, L. H. A critical role of TRPM2 channel in $A \beta_{42}$-induced microglial activation and generation of tumor necrosis factor-alpha. Glia 66, 562-575 (2018).

44. Yamamoto, S., Wajima, T., Hara, Y., Nishida, M. \& Mori, Y. Transient receptor potential channels in Alzheimer's disease. Biochim. Biophys. Acta 1772, 958-967 (2007).

45. Alberdi, E. et al. Amyloid beta oligomers induce $\mathrm{Ca}^{2+}$ dysregulation and neuronal death through activation of ionotropic glutamate receptors. Cell Calcium 47, 264-272 (2010).

46. Olah, M. E. et al. $\mathrm{Ca}^{2+}$-dependent induction of TRPM2 currents in hippocampal neurons. J. Physiol. 587, 965-979 (2009).

47. Koh, J. Y. et al. The role of zinc in selective neuronal death after transient global cerebral ischemia. Science 272, 1013-1016 (1996).
48. Myers, S. A., Nield, A. \& Myers, M. Zinc transporters, mechanisms of action and therapeutic utility: implications for type 2 diabetes mellitus. J. Nutr. Metab. 2012, 173712 (2012)

49. Yang, $W$. et al. Zinc inactivates melastatin transient receptor potential 2 channels via the outer pore. J. Biol. Chem. 286, 23789-23798 (2011).

50. Toth, B. \& Csanady, L. Identification of direct and indirect effectors of the transient receptor potential melastatin 2 (TRPM2) cation channel. J. Biol. Chem. 285, 30091-30102 (2010).

51. Du, J., Xie, J. \& Yue, L. Intracellular calcium activates TRPM2 and its alternative spliced isoforms. Proc. Natl Acad. Sci. USA 106, 7239-7244 (2009).

52. Feng, $\mathrm{S}$. et al. Canonical transient receptor potential 3 channels regulate mitochondrial calcium uptake. Proc. Natl Acad. Sci. USA 110, 11011-11016 (2013).

53. Sensi, S. L. et al. Modulation of mitochondrial function by endogenous $\mathrm{Zn}^{2+}$ pools. Proc. Natl Acad. Sci. USA 100, 6157-6162 (2003).

54. Kleinschnitz, C. et al. Post-stroke inhibition of induced NADPH oxidase type 4 prevents oxidative stress and neurodegeneration. PLOS Biol. 8, e1000479 (2010).

55. Radermacher, K. A. et al. Neuroprotection after stroke by targeting NOX4 as a source of oxidative stress. Antioxid. Redox Signal. 18, 1418-1427 (2013).

56. Choi, D. H. et al. NADPH oxidase 1, a novel molecular source of ROS in hippocampal neuronal death in vascular dementia. Antioxid. Redox Signal. 21, 533-550 (2014)

57. Domercq, M. et al. $\mathrm{Zn}^{2+}$-induced ERK activation mediates PARP-1-dependent ischemic-reoxygenation damage to oligodendrocytes. Glia $\mathbf{6 1}, \mathbf{3 8 3 - 3 9 3}$ (2013).

58. Zou, J. et al. A differential role of macrophage TRPM2 channels in $\mathrm{Ca}^{2+}$ signaling and cell death in early responses to $\mathrm{H}_{2} \mathrm{O}_{2}$. Am. J. Physiol. Cell. Physiol. 305, C61-C69 (2013).

59. Beaudoin, G. M. 3rd et al. Culturing pyramidal neurons from the early postnatal mouse hippocampus and cortex. Nat. Protoc. 7, 1741-1754 (2012).

60. McHugh, D., Flemming, R., Xu, S. Z., Perraud, A. L. \& Beech, D. J. Critical intracellular $\mathrm{Ca}^{2+}$ dependence of transient receptor potential melastatin 2 (TRPM2) cation channel activation. J. Biol. Chem. 278, 11002-11006 (2003).

61. Bonanni, L. et al. Zinc-dependent multi-conductance channel activity in mitochondria isolated from ischemic brain. J. Neurosci. 26, 6851-6862 (2006).

62. Dunn, K. W., Kamocka, M. M. \& McDonald, J. H. A practical guide to evaluating colocalization in biological microscopy. Am. J. Physiol. Cell Physiol. 300, C723-C742 (2011)

63. Koopman, W. J. et al. Inhibition of complex I of the electron transport chain causes $\mathrm{O}_{2}$ mediated mitochondrial outgrowth. Am. J. Physiol. Cell Physiol. 288, C1440-C1450 (2005). 